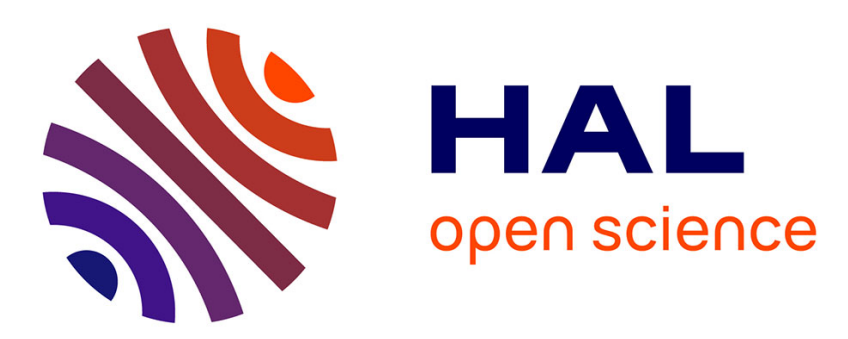

\title{
Recherches archéologiques dans le cloître Saint-Sauveur d'Aix-en-Provence: bilan de quatre campagnes de fouilles (1976-1979)
}

\author{
Rollins Guild, Jean Guyon, Lucien Rivet
}

\section{To cite this version:}

Rollins Guild, Jean Guyon, Lucien Rivet. Recherches archéologiques dans le cloître Saint-Sauveur d'Aix-en-Provence: bilan de quatre campagnes de fouilles (1976-1979). Revue archéologique de Narbonnaise, 1980, 13 (1), pp.115-164. 10.3406/ran.1980.1052 . halshs-00204557

\section{HAL Id: halshs-00204557 \\ https://shs.hal.science/halshs-00204557}

Submitted on 13 Apr 2018

HAL is a multi-disciplinary open access archive for the deposit and dissemination of scientific research documents, whether they are published or not. The documents may come from teaching and research institutions in France or abroad, or from public or private research centers.
L'archive ouverte pluridisciplinaire HAL, est destinée au dépôt et à la diffusion de documents scientifiques de niveau recherche, publiés ou non, émanant des établissements d'enseignement et de recherche français ou étrangers, des laboratoires publics ou privés. 
Recherches archéologiques dans le cloître de Saint-Sauveur d'Aixen-Provence. Bilan de quatre campagnes de fouilles (1976-1979)

Rollins Guild, Jean Guyon, Lucien Rivet

\section{Citer ce document / Cite this document :}

Guild Rollins, Guyon Jean, Rivet Lucien. Recherches archéologiques dans le cloître de Saint-Sauveur d'Aix-en-Provence. Bilan de quatre campagnes de fouilles (1976-1979). In: Revue archéologique de Narbonnaise, tome 13, 1980. pp. 115-144; doi : 10.3406/ran.1980.1052

http://www.persee.fr/doc/ran_0557-7705_1980_num_13_1_1052

Document généré le 19/06/2017 


\title{
RECHERCHES ARCHÉOLOGIQUES DANS LE CLOÎTRE SAINT-SAUVEUR D'AIX-EN-PROVENCE
}

\author{
Bilan de quatre campagnes de fouilles \\ (1976 - 1979)
}

Les travaux de restauration du cloitre de la cathédrale Saint-Sauveur d'Aix-en-Provence ont été l'occasion d'une fouille d'urgence pour étudier ce site mal connu (1) placé dans une zone qui fut de tout temps au cœur de l'agglomération (2) (fig. 1).

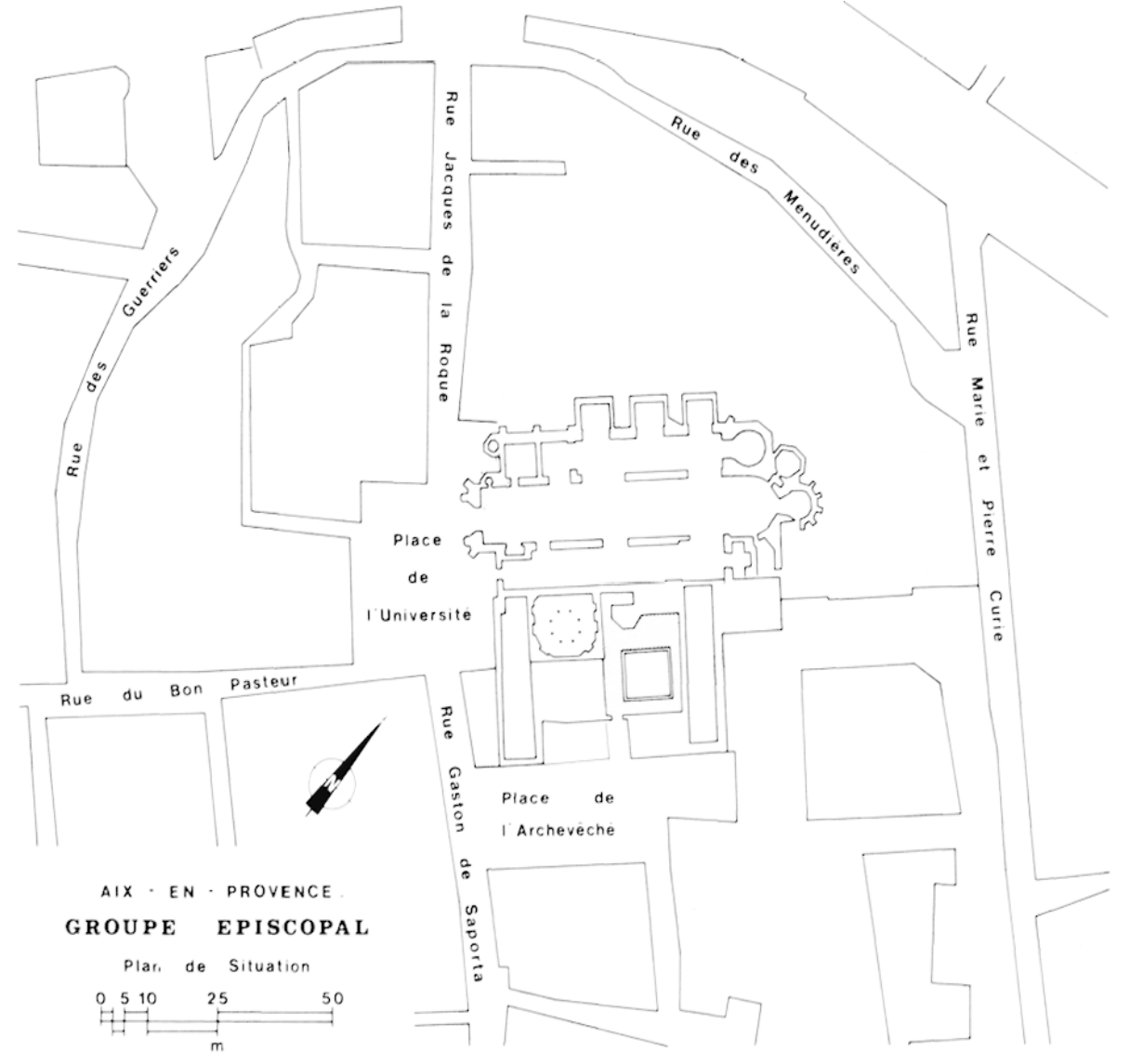

Fig. 1. - Plan de situation du groupe épiscopal d'Aix (en grisé, le cloitre).

La rue des Guerriers et la rue des Menudières marquent la limite N. du Bourg Saint-Sauveur, l'une des trois "villes " (avec la " ville comtale " au S. et la " ville des Tours" plus à l'O.) installée au Moyen-Age sur l'emplacement de la ville antique.

(1) Les dernières fouilles sur le site remontent à 1958; elles ont porté à la fois sur le cloitre et le baptistère : cf. Informations archéologiques. dans Gallia. 16. 1958, p. 415-417 (F. Benoit).

(2) Pour une présentation de la topographie et de l'histoire antique d'Aix, voir en dernier lieu la contribution de P.-A. Février à l'ouvrage collectif Histoire d'Aix-en-Provence. 1977. p. 36-59. et le plan de la p. 37 qui montre la situation de la cathédrale Saint-Sauveur au croisement des deux seuls axes antiques de circulation qu'on ait plus ou moins sürement reconnus à Aix (sur ce point. cf. aussi notre fig. 6. et les n. 10-11, p. 118). 
L'intérêt de la fouille était multiple : l'historien de l'antiquité classique pouvait espérer y trouver une stratigraphie - sinon des vestiges - remontant jusqu'à la fondation de la ville; le spécialiste de l'antiquité tardive, quelques lumières sur les origines chrétiennes d'Aix par la reconnaissance du baptistère qui jouxte le cloître au N.-O. (3); le médiéviste et le moderniste enfin, une meilleure connaissance des bâtiments claustraux débarrassés de leurs enduits.

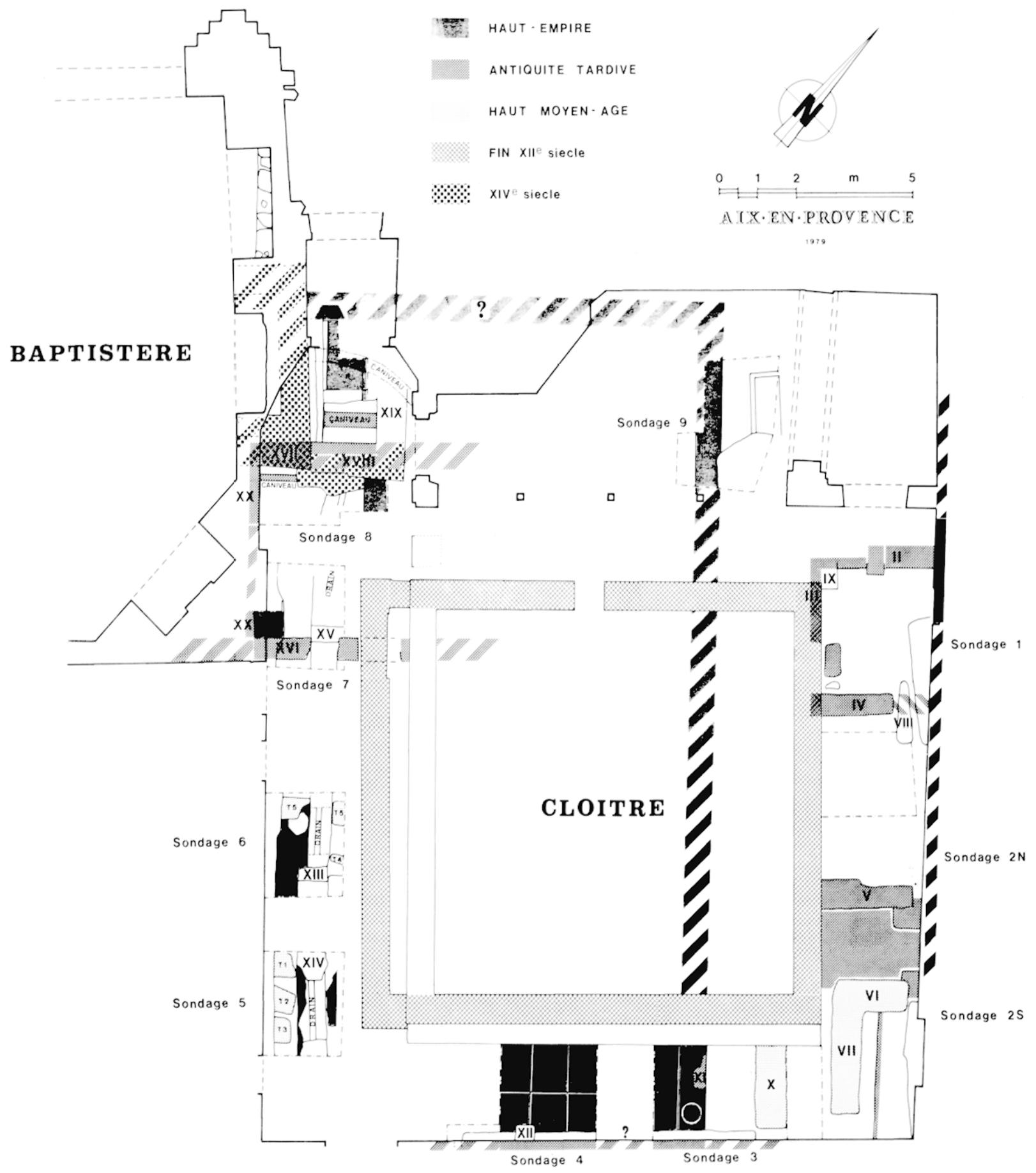

Fig. 2. - Plan de localisation des sondages.

(3) Nous avons choisi d'adopter pour cet article un N. conventionnel, en considerant la cathédrale Saint-Sauveur comme un bâtiment exactement orienté : la nomenclature des differentes orientations est ainsi grandement simplifièe.

$\mathrm{Ce} \mathrm{N}$. coïncide avec l'aplomb de nos dessins, sur lesquels est également reporté le $\mathrm{N}$. géographique. 
Neuf sondages ont èté ouverts (4) (fig. 2) :

- les sondages $1(3 \mathrm{~m} \times 4,50 \mathrm{~m}$ ) et 2 . N. et $\mathrm{S}$. (un sondage de $2.50 \mathrm{~m} \times 7 \mathrm{~m}$ séparé conventionnellement en deux par le mur VI) dans la galerie 0 . en 1976 ;

- les sondages $3(3,50 \mathrm{~m} \times 2 \mathrm{~m})$ et $4(2.50 \mathrm{~m} \times 2 \mathrm{~m})$ dans la galerie S. en 1977 ;

- les sondages 5 à $7(2 \mathrm{~m} \times 2,50 \mathrm{~m})$ et $8(4 \mathrm{~m} \times 5 \mathrm{~m})$ dans la galerie 0 . en 1978;

- le sondage $9(2.50 \mathrm{~m} \times 3 \mathrm{~m})$ dans la galerie $\mathrm{N}$. en 1979 .

Ils ont apporté à la fois plus et moins qu'on pouvait en attendre; malgré leur caractère fragmentaire et la nécessité d'investigations complémentaires, il nous a paru utile pourtant d'exposer en suivant un ordre chronologique les acquis de notre enquête accompagnés d'un jeu raisonnable d'hypothèses interprétatives.

\section{ANTIQUITÉ ET HAUT MOYEN-ÂGE}

\section{AU HAUT-EMPIRE : UNE COUR DALLEE ET UN PORTIQUE}

A la cote moyenne 202,81 N.G.F. (5) - soit 2,15 m environ au-dessous du sol du cloitre - ont été retrouvés dans le secteur occidental de la fouille les restes d'un sol fait de grandes dalles de pierre froide mesurant en moyenne $1,65 \mathrm{~m}$ de long pour $0,95 \mathrm{~m}$ de large et disposées longitudinalement selon un axe N.-S. (fig. 3).

A l'E. au moins, un stylobate limite la cour dallée. Dans le sondage 3 il est fait d'un grand bloc en pierre froide mesurant $0,70 \mathrm{~m}$ de large et $0,30 \mathrm{~m}$ de haut pour une longueur exacte inconnue, supérieure à celle du sondage $(2 \mathrm{~m})$; il porte un canal de coulée pour la fixation au plomb d'une base de colonne aujourd'hui disparue (fig. 4). Le sol associé au bloc est recouvert d'un mortier rose très dégradé.

Le stylobate n'est bien conservé que dans ce sondage où il repose sur une assise de cailloux posés à mème le rocher; dans le sondage 9 le bloc en pierre froide a disparu et seules subsistent ses fondations - un mortier tenace de couleur orangée sommant un lit de cailloutis épais de $0,20 \mathrm{~m}$.

De même les dalles de la cour sont très inégalement conservèes : intactes et comme neuves dans le sondage 4 (à l'exception d'un exemplaire à la surface inégale et déprimée qui aurait pu servir de support à une base ? ou une statue ?), elles ont été endommagées dans les sondages 5 à 8 par une profonde tranchée d’époque médiévale (infra, p. 139); partiellement absentes des sondages 7 et 8 , elles ont totalement disparu dans le sondage 9. Dans le sondage 3 la dalle jouxtant le stylobate est à la fois plus grossière et plus longue qu'à l'ordinaire : on n'a pu trouver ses limites à cause des dimensions trop réduites de la zone fouillée.

C'est sur les parois de la tranchée précédemment signalée qu'on a pu étudier dans les sondages 6 et 7 les fondations du dallage : les dalles, èpaisses d'une quinzaine de $\mathrm{cm}$, reposent, par l'intermédiaire d'un lit de pierres plates et de mortier épais de. $0,10 \mathrm{~m}$, sur un hérisson de cailloutis de $0,15 \mathrm{~m}$ d’épaisseur qui recouvre lui-mème une série de couches rapportées (ou d'occupation?) épaisses de $0,15 \mathrm{~m}$ à $0,30 \mathrm{~m}$ égalisant la surface irrégulière de l'argile orangée sous-jacente (cf. fig. 25).

Ces éléments suffisent à assurer l'existence d'une cour bordée au moins à l'E. d'un portique; d'autres indices peuvent aider à préciser la configuration de cet ensemble monumental.

(4) Sondages effectues par les auteurs de ce rapport. avec la collaboration de D. Foy pour la campagne de 1976.

La bonne coordination des travaux entre les services de la Conservation des Bátiments de France (M. Dufoix. architecte en chef des Monuments historiques: M. Pellissier. architecte des Bâtiments de France) et la Direction des Antiquités historiques de Provence (M. Salviat. Directeur) a grandement facilité la fouille. qui a également bénéficiè de la compréhension des utilisateurs de la cathédrale. clercs et laics.

Mlle G. Démians d'Archimbaud. MM. P.-A. Février et C. Goudineau. professeurs à I'Université de Provence. ont suivi de très près notre travail, sur le terrain ou au moment de l'exploitation des resultats.

Enfin. Mlles C. Brenot et L. Vallauri: MM. R. Ambard. N. Coulet et J.P. Pelletier nous ont apporté l'aide de leurs conseils et de leur compétence.

Que tous veuillent bien trouver ici l'expression de nos remerciements.

(5) Cote établie à partir du repere N.G.F. $207.28 \mathrm{~m}$ figurant sur la façade de la cathédrale au N. du porche. 
Pour la cour seule la limite E. est sûre : au S., il est certain que le dallage se poursuit au-delà de la zone fouillée en direction de la place des Martyrs de la Résistance (ancienne place de l'Archevêché); à l'O., il est vraisemblable qu'il continue également audessous du baptistère (6); au $\mathrm{N}$. enfin une reconnaissance rapide dans la paroi $\mathrm{N}$. du sondage 8 nous a permis d'apercevoir au-delà de la dernière dalle un bloc qui pourrait appartenir à un stylobate N., mais, faute d'avoir pu pratiquer un sondage de vérification, l'interprétation ne peut que rester hypothétique (cf. fig. 28).

La restitution du portique attenant est également difficile. Ses colonnes de $0.60 \mathrm{~m} / 0.65 \mathrm{~m}$ de diametre environ, dont on a peut-êtrc retrouvé des bases - mais non les fûts - dans la fouille (7). laissent supposer une élévation de 5 à $6 \mathrm{~m}$ et une largeur équivalente. Or, à $5,60 \mathrm{~m}$ environ à l'E. du stylobate et sensiblement parallèle à lui (8) ont été reconnus les restes d'un mur - I en petit appareil relativement soignè (fig. 5), qui pourrait convenir à cette restitution.

Les données de la fouille sont cependant trop fragmentaires pour qu'on puisse l'affirmer : le mur, qui sert aujourd'hui de fondation au mur $E$. du cloître, n'a été reconnu que sur sa face 0 . et sur une longueur de $3 \mathrm{~m}$; encore est-il partiellement masqué, au N. par les restes d'un praefurnium postérieur (infra, p. 121-123) et au S. par un contrefort tardif du mur du cloitre, de sorte qu'il n'est complètement visible en élévation que sur une longueur de $1,80 \mathrm{~m}$. On observera seulement que ses fondations qui s'enfoncent dans le sol vierge argileux affleurent à la cote 203,11 N.G.F., soit exactement au niveau du stylobate. Ce fait, comme la similitude d'orientation, va bien dans le sens de l'interprétation proposée, mais la construction du praefurnium a fait disparaitre toute trace du sol primitif, en mème temps qu'elle a peut-être entrainé des remaniements à la base du mur (9), de sorte que toute vérification précise est interdite.

Telles sont les données - très fragmentaires - de la fouille. A partir d'elles, nous croyons qu'il est possible de proposer la restitution suivante : il y avait dans l'Antiquité à l'emplacement du cloître une cour dallée bordée, au moins à l'E., et peut-être aussi au N., par un portique large de 5,60 m environ (fig. 6).

Dans cette restitution, la partie la plus hypothétique est certainement l'aile $\mathrm{N}$. du portique, qui s'étendrait presque exactement sous l'emplacement des chapelles flanquant la nef S. de la cathédrale. Nous la croyons pourtant vraisemblable pour deux raisons au moins : d'une part une restitution possible de la colonnade (celle qui est représentée sur la figure 6) conduit à placer une colonne exactement à l'angle N.-E. supposé de la cour; d'autre part, le mur N. du portique serait alors à peu près dans l'alignement du mur $\mathrm{N}$. du baptistère, qui aurait pu partiellement réutiliser son élévation s’il s’agit bien d’un édifice antique, comme il est possible (infra, p. 129-130).

L'interprétation de cet ensemble monumental (la surface de la cour restituable à coup sûr dépasse $200 \mathrm{~m}^{2}$, auxquels il faudrait ajouter une superficie au moins égale pour le portique supposé) ne laisse pas d'être difficile.

La cour et le portique se situent à proximité immédiate d'un cardo reconnu en 1958 (10), mais barrent sans doute la route d'un decumanus (qu'on situe généralement à l'emplacement de l'actuelle rue du BonPasteur) dont on n'a pas trouvé trace dans la fouille (11). Ce pourrait être un argument pour penser que la cour et son portique s'étendent vers l'O. jusqu'au cardo, ou du moins jusqu'au mur - sans doute antique -

(6) Sur l'une des dalles du sondage 7 on a bien retrouve un canal de coulée pour la fixation au plomb d'une base: mais la dalle est sensiblement au mème niveau que ses voisines. et il est exclu de l'interpréter comme un élément de stylobate. Sans doute faut-il supposer que le sol de la cour portait des bases ou des colonnes.

(7) Une base - très fruste il est vrai - retrouvée dans les remblais du sondage 2: une autre en place dans les fondations du mur III du praefurnium du sondage I (infra, p. 121): les élements de füts sont en revanche absents. Mais il n'est pas exclu que certaines des colonnes en remploi du baptistère voisin. plutôt que de provenir du "temple d'Apollon " que la tradition place dans cette zone. soient directement issues de la démolition ou la desaffectation du portique : leur hauteur moyenne de $5.50 \mathrm{~m}$ environ conviendrait bien en tout cas à cet édifice.

(8) Le mur a été reconnu sur une trop brève longueur pour qu'on puisse connaitre son orientation en toute certitude: il est sür pourtant que le mur médiéval qu'il supporte (illfra, p. 134) est légèrement désaxé par rapport à lui.

Cette différence d'orientation er:re les constructions antiques et médiévales est une constante sur le site (cf. fig. 2) et on la retrouve jusque dans les édifices ètablis en lisière du cardo: F. Benoit. loc. cil. p. 416.

(9) Les assises inférieures de moellons. passablement dégradées. sont couvertes d'un enduit de tuileaux et la base de l'élévation constituée d'un grand bloc monolithe (cf. fig. 5 et 16) : c'est sans doute l'indice d'une réfection quion ne peut autrement dater.

(10) F. Benoit, loc. cil., p. 416 et fig. 8, avec renvoi à la trouvaille antérieure d'un autre fragment du mème cardo, rue Paul-Bert : Gallia. 12. 1954, p. 299 et fig. 13: une troisième portion de ce cardo a depuis été retrouvée. rue Chabrier: voir R. Amy. Découverte d'une portion de voie romaine à Aix-en-Provence, dans R.A.N., I, 1968, p. 251-256.

(11) C'est le decumanus situé dans le lointain prolongement d'une portion de voie dégagée aux portes de la ville (cf. $R$. Ambard G. Bertucchi - J.-M. Gassend, Fouilles d'urgence et découverte du decumanus à Aix-en-Provence, dans R.A.N., 5, 1972, p. 31-47) qui figure sur le plan cité p. 115, n. 1 .

L'axe du decumanus restitué traverserait le site entre les sondages 1 et 2 et 6 et 7 : les bermes entre ces sondages sont trop réduites (respectivement 2 et $3 \mathrm{~m}$ ) pour laisser place à une rue sous les zones que nous n'avons pu fouiller. 


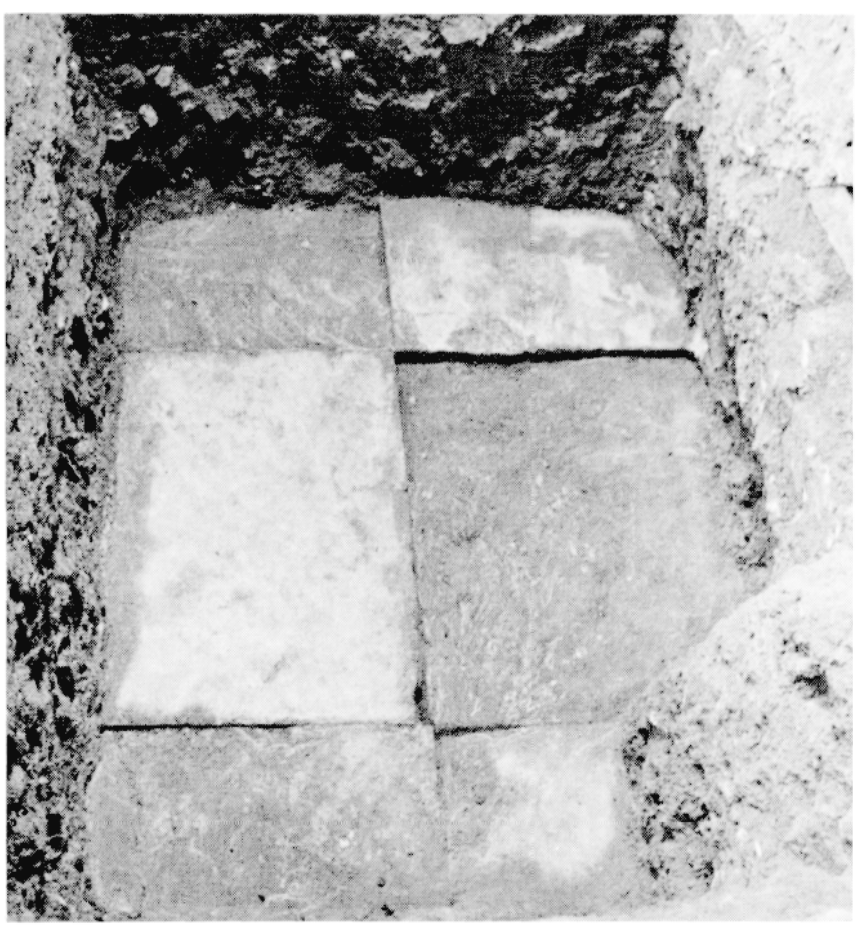

Fig. 3. - Sondage 4.

Le dallage du Haut-Empire vu de l'O.

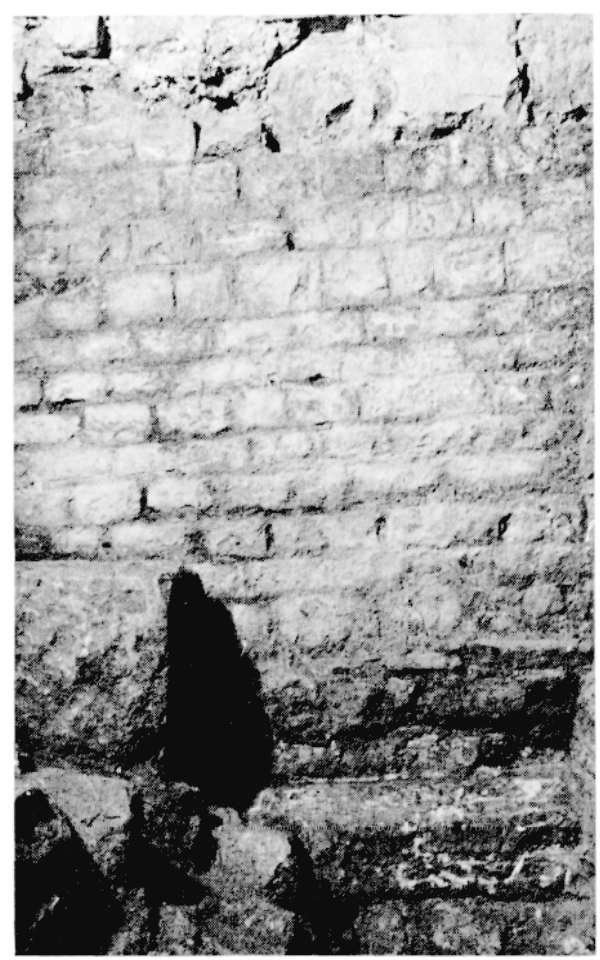

Fig. 5. - Sondage 1.

Le mur l vu de l'O. (noter la présence d'un grand bloc à la base de l'élévation); en $h$., reprise médiévale au-dessus du mur antique; à g., bloc appartenant à la paroi E. du praefurnium.

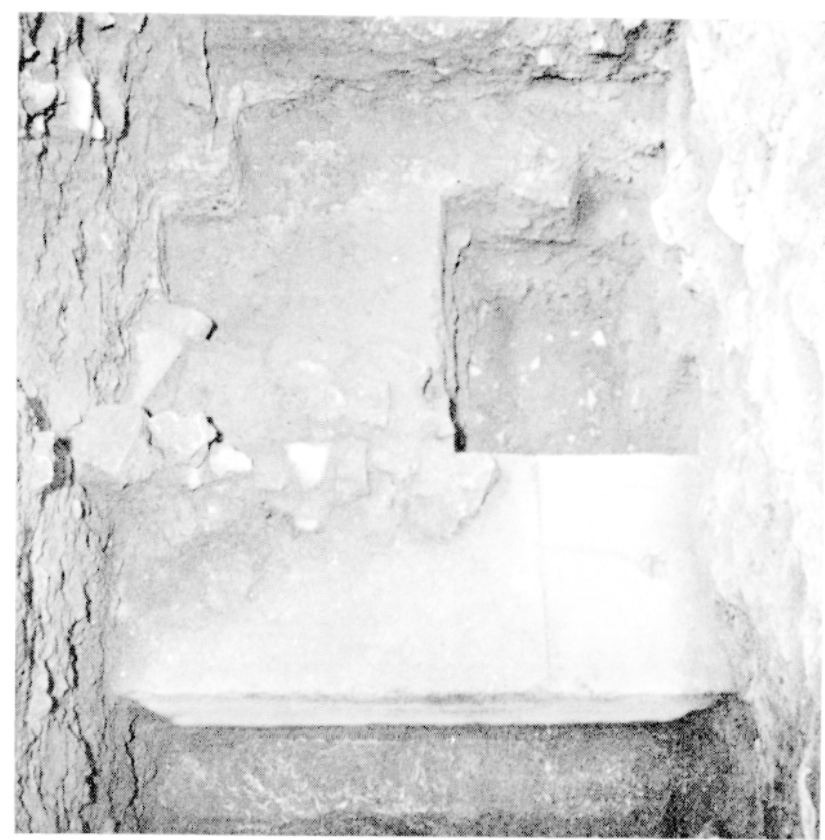

Fig. 4. - Sondage 3.

Le stylobate vu de l'O. (noter l'emplacement réservé à d. pour la colonne disparue). A g. sur le stylobate, restes du mur XI; au fond sur les parois. stratigraphie d'un foyer de la BasseAntiquité.

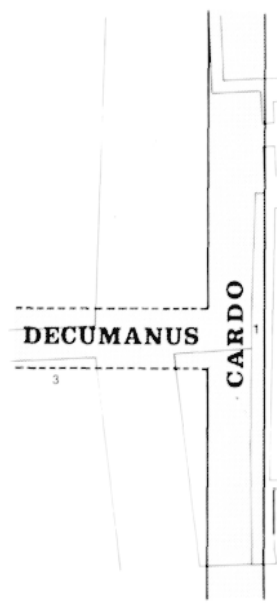

Fig. 6. - Schéma de situation au Haut-Empire 1 : alignement approximatif du cardo devant la façade de la cathédrale romane (fouille de 1958); 2 : mur en petit appareil visible dans la "cave aux huiles "; 3 : emplacement hypothétique du decumanus (dans l'axe de la rue du Bon-Pasteur). 
que l'on peut observer dans la « cave aux huiles " voisine (12) (cf. fig. 6); à tout le moins jugera-t-on qu'une telle interruption du carroyage des rues suppose l'existence d'un monument important, probablement de même niveau que les rues voisines (13).

Plutôt qu'à la cour d'un édifice privé, dont l'ampleur serait un peu surprenante, on pourrait songer à la cour d'un édifice public, ou encore à une petite place publique ( $37 \mathrm{~m}$ au maximum d'E. en 0 .) réservée aux piétons (les dalles ne présentent aucune trace d'ornière) : hic erat forum titrait la presse locale au moment de nos recherches... Toutes les hypothèses sont possibles tant que les surfaces fouillées resteront aussi réduites.

L'intérêt du monument, pour l'instant, tient surtout à sa datation. Sans doute convient-il d'être très prudent, car les sondages au-dessous du niveau des dalles n'ont livré qu'un nombre limité de fragments de céramique datables (couches 7 a à 7 d, sondages 5 à 8 - mais aussi sondage 9 -, fig. 30 et fig. 36 à 40); du moins le matériel recueilli est-il homogène et interdit-il de placer avant le dernier quart du premier siècle de notre ère la création de la cour.

Or cette date relativement tardive est aussi, selon toute apparence, celle de l'apparition du premier établissement important sur le site.

On a bien rencontré, dans une zone d'ailleurs très perturbée du sondage 8. des traces d'une installation peut-ètre antérieure au dallage qu'il a été impossible de fouiller vraiment (14), mais partout ailleurs, comme on l'a déjà signalé, la cour et le portique reposent sur le sol naturel (argile ou rocher) par l'intermédiaire d'une couche relativement mince de remblai. Sauf à supposer un abaissement - toujours possible - du niveau à l'occasion de l'édification de la cour, il semble bien qu'elle ait été le premier monument créé dans cette zone. On le croira d'autant plus volontiers que cette conclusion s'accorde parfaitement avec le matériel céramique recueilli dans l'ensemble des sondages, qui ne contient qu'en proportion infime des tessons antérieurs à la fin du Ir siècle (cf. fig. 30).

Si des sondages plus étendus et plus nombreux dans cette zone relativement centrale d'Aix antique devaient confirmer les résultats de la fouille du cloitre, on devrait en tirer des conséquences importantes pour l'histoire de la ville : l'édification d'Aquae Sextiae n'aurait été que très progressive si vraiment des secteurs entiers n'ont connu aucune occupation humaine - en tout cas aucune occupation importante avant les années 80-100 de notre ère, soit plus de deux siècles après la première création de Sextius Calvinus (15).

Pour tardive qu'elle soit, la création de la cour et du portique n'en a pas moins été importante pour l'histoire urbaine : de la fin du ${ }^{\text {er }}$ siècle à nos jours cette partie d'Aix est restée une zone non bâtie, la place des Martyrs de la Résistance (ancienne place de l'Archevêché) ayant remplacé la cour romaine, tandis que les colonnades du cloitre peuvent évoquer, plus modestement, celles du portique qui l'entourait. Il y a là une permanence remarquable qui valait la peine d'être soulignée.

(12) Ce mur pourrait avoir servi de limite commune au portique et au trottoir de largeur modeste $(0,90 \mathrm{~m}$ : F. Benoit, loc. cit., p. 416) qui longe le cardo: conservé sur $4 \mathrm{~m}$ de long entre les cotes 202,81 et $203,61 \mathrm{~m}$, il est constitué de moellons parallélépipédiques bien calibrés similaires à ceux du mur 1.

(13) Les indications de niveau fournies par le rapport de F. Benoit sur les fouilles de 1958 sont contradictoires : loc. cit., p. 416, il signale que le cardo est "à $-2.10 \mathrm{~m}$ sous le niveau de la place (scil. de l'Université)", soit à peu près au même nivéau que le dallage que nous avons retrouvé: quelques lignes plus haut. il indique au contraire que le niveau actuel du baptistère est "à $0.60 \mathrm{~m}$ environ au-dessus de la voie romaine ", ce qui conduirait à placer le cardo nettement plus haut (cf. fig. 27). De ces deux indications, on préferera la première, plus objective et donc moins susceptible d'être entachée d'erreur.

(14) II s'agit d'un massif de blocage que l'on a entrevu au-dessous du dallage au N. du mur XVIII (cf. fig. 28): sa cote invite à le considérer comme antérieur au dallage: mais il est également possible qu'il fasse partie d'une reprise antique en sous-œuvre dans une zone très humide (les caniveaux y abondent. à toutes les époques) et où les effondrements ont été fréquents.

(15) L'hypothèse n'est pas gratuite : les fouilles du decumanus aux portes de la ville ont montré que le remblai dominant la voie n'a été aménagé lui aussi qu'à la fin du er siècle (cf. $R$. Ambard et alii, loc. cit.), et, d'une façon générale, les fouilles sporadiques faites à Aix n'ont jamais permis de retrouver des monuments, ou seulement des niveaux d'occupation, antérieurs au jer siècle de notre ère. 


\section{LES TRANSFORMATIONS DE LA BASSE-ANTIQUITÉ : UN VASTE PROGRAMME DE CONSTRUCTIONS CIVILES OU RELIGIEUSES}

Les transformations du site dans la Basse-Antiquité ont été si radicales qu'elles prennent l'allure d'un véritable bouleversement qui touche cependant inégalement différents secteurs : tandis qu'à l'O. et peut-être aussi au S. sont édifiés des bâtiments relativement importants, l'E. est plus sporadiquement occupé par des constructions de fortune et des pièces de service.

On a choisi de décrire séparément ces réoccupations avant d'en proposer une interprétation globale.

\section{DESCRIPTION}

\section{a. Des bâtiments de service et des réoccupations de fortune à l'E.}

\section{Les bâtiments de service}

\section{- $A$ u N.-E. dans le sondage 1 un praefurnium (fig. 7).}

C'est un espace de dimensions modestes $\left(8 \mathrm{~m}^{2}\right.$ environ) de plan carré de $2,80 \mathrm{~m}$ de côté, clos par des murs de facture assez négligée.

Son mur E. n'est autre que le mur I, précédemment décrit comme mur extérieur du portique.

Son mur S. - ou mur IV - a été détruit à l'E. par la construction d'un puissant contrefort tardif du mur E. du cloitre; à l'O. en revanche il est presque entièrement conservé, et seul a disparu le parement S. de la porte qui s'ouvrait dans l'angle S.-O. Large de $0,50 \mathrm{~m}$, ce mur est composé de moellons relativement calibrés liés par un mortier blanchâtre. Les fondations, profondes de $0,20 \mathrm{~m}$, reposent sur la couche d'argile naturelle à la cote 202,91 N.G.F. Le sommet du mur a été soigneusement écrêté à la cote $204,16 \mathrm{~m}$.

Son mur O. - ou mur III - n'a été reconnu que sur sa face E. où il présente une facture analogue à celle du mur IV. Il est percé au S. d'une porte large de $1,20 \mathrm{~m}$ dont le parement $\mathrm{N}$. est bien conservé dans la partie inférieure: en revanche. la construction à époque médiévale tardive d'un puissant pilier de fondation dans l'angle N.-O. (infra, p. 140) empêche de lire sa liaison avec le mur $\mathbf{N}$. Les fondations. de cote trés comparable à celles du mur III, sont faites de moellons de grande taille et de matériel de remploi (dont une base de colonne en marbre de $0.64 \mathrm{~m}$ de diamètre). Sur le sommet du mur régulièrement écrêté reposent les fondations du stylobate du cloitre.

Son mur N. - ou mur II - a été détruit sur plus de la moitié de sa longueur par une coulée de béton très récente. Cette construction masque la plus grande partie de la sole du praefurnium qui s'ouvre sur cette paroi : il en subsiste cependant le montant E. fait de grands blocs de calcaire rose sommairement liès à l'argile qui appartiennent peut-être à une réfection, car leur facture négligée tranche sur les restes d'un parement en briques dont on devine les traces au long de la coulée de béton. La sole est faite d'une grande pierre de couleur brune qui saille d'une dizaine de $\mathrm{cm}$ par rapport au droit du mur. dans l'axe de la pièce. En fondation, de part et d'autre de cette pierre et jusquà son niveau d'affleurement $(203,03 \mathrm{~m})$ on compte deux assises très règulières à l'O. et trois à l'E. faites de briques de $30 \times 45 \times 45 \mathrm{~cm}$ au contact de la pierre, puis de moellons soigneusement appareillés à mesure qu'on s'en éloigne. Ces fondations ont été établies dans le sol naturel en creusant une tranchée qui n’a livré aucun matériel.

Dans tout cet espace, le sol s'abaisse lentement des bords vers le centre, le niveau de la sole étant environ $0,20 \mathrm{~m}$ au-dessous de celui du seuil constitué de deux grands blocs en pierre froide - des remplois très probablement. Au long des murs $\mathrm{E}$. et $\mathrm{O}$. le sol est fait d'un lit de cailloutis assez résistant qui a peut-être disparu au centre, oủ l'on ne trouve plus qu'un niveau d'argile et de cendres.

Malgré une similitude de cote trompeuse entre le niveau de la sole et celui du portique il scrait faux de croire que ce bâtiment de service a été simplement édifié sur le niveau préexistant : l'abondance de la cendre et de matériaux de remploi (notamment du marbre de placage), non seulement dans la couche au-dessous du sol, mais dans les fondations des murs périmétraux montre qu'on a surcreusé de $0.30 \mathrm{~m}$ environ le sol du portique au moment de la création du praefurnium (16).

(16) It n'y a pas de traces de cendres dans la couche la plus profonde du sondage 2, qui correspond sans doute au sol du portique. ni surtout dans les couches associees au stylobate dans le sondage 3. 


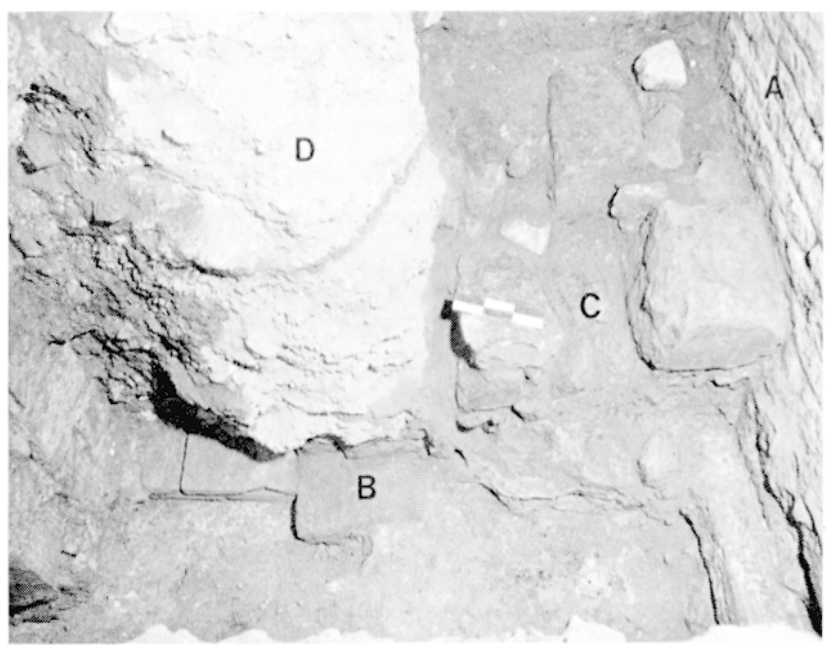

Fig. 7. - Sondage 1.

Le praefurnium vu du S.

A : mur I : B : sole du praefurnium; C : paroi E. (partiellement démontée): $\mathrm{D}$ : coulèe moderne de beton.

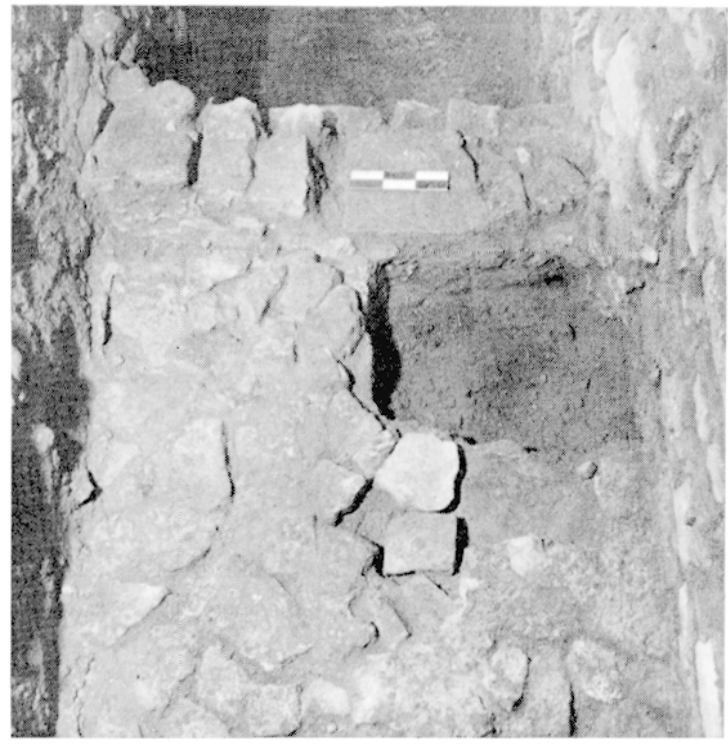

Fig. 8. - Sondage $2 \mathrm{~N}$.

La seconde pièce de service vue du S. : Hérisson d'apprêt pour le second sol en béton (partiellement déposè); au fond (jalon), le mur $\mathrm{V}$.

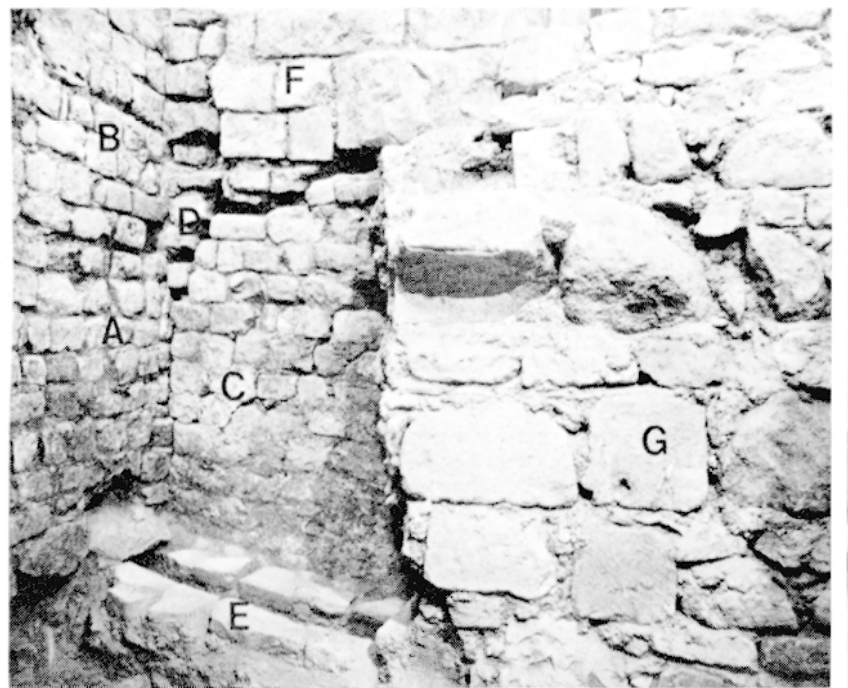

Fig. 9. - Sondage 8.

Vue partielle du S.-E. (au S. du mur XVII).

$A$ : mur XX, partie inférieure: $B$ : mur XX, partie supérieure:

$C$ : mur XVII, partie inférieure appuyée contre le mur $X X$ :

$\mathrm{D}$ : mur XVII, partie supérieure liee au mur $\mathrm{XX} ; \mathrm{E}$ : caniveau; $F$ : fondations de la niche médiévale de la paroi $E$. du baptistère; $\mathrm{G}$ : renfort tardif du mur XVIII. (cliché C.N.R.S. -

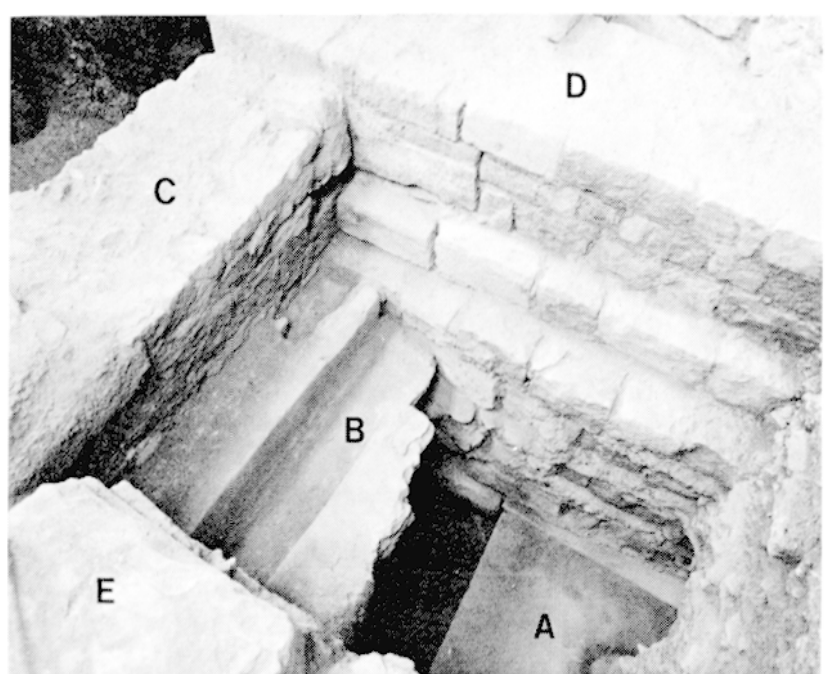

Fig. 10. - Sondage 8.

Vue partielle du N.-E. (au N. du mur XVII). A : dalle du Haut-Empire; B : caniveau; C : mur XVII : D : niche médiévale de la paroi $\mathrm{E}$. du baptistère; $\mathrm{E}$ : mur XIX. (Cliché C.N.R.S. - Chéné-Foliot).

$$
\text { Chéné - Foliot). }
$$


Il est clair que la construction du praefurnium témoigne d'une désaffectation au moins partielle de l'aile E. du portique qu'attestent non seulement le surcreusement du sol et les remplois, mais encore la construction au $\mathrm{N}$. du praefurnium et à un niveau surélevé d'une salle ou d'un bâtiment qu'il servait à chauffer et qu'il nous a été impossible de fouiller.

Cette désaffectation du portique serait assez tardive ( $v^{\mathrm{e}}$ siècle ?) car le matériel céramique datable contenu dans la couche au-dessous du sol du praefurnium semble contenir, à côté de tessons plus anciens, de la céramique sigillée claire luisante (?) et de la céramique sigillée claireD (?) (couche $5 \mathrm{~b}$, sond. 1, fig. 30 , et commentaire de la fig. 31).

C'est sans doute l'utilisation du praefurnium qui a donné lieu au dépót au-dessus du sol d'une couche archéologique - 5a d'une trentaine de $\mathrm{cm}$ d'épaisseur, très riche en débris de cendres et de charbon de bois alternant avec des dépôts d'argile et de terre qui donnent à l'ensemble de la couche un aspect feuilleté en stratigraphie (cf. fig. 23). Cette couche a donc èté déposée par apports successifs et prolongés conduisant à un exhaussement progressif du niveau: sa tranche supérieure en tout cas a servi de sol : au N., elle est recouverte d'une mince pellicule de mortier au-dessus de laquelle repose une couche de destruction et de remblai.

Ce niveau, qui contient de la céramique sigillée estampée grise pourrait ètre daté de l'extrême fin de l'Antiquité. époque à laquelle on a sans doute procédé à la réfection, déjà signalée, de la chambre de chauffe. car le démontage partiel de sa paroi $E$. a fourni une ceramique analogue (niveau 4/5, sond. 1 . fig. 30 et 31 ). Cette réparation - commune dans une installation aussi fragile - pourrait marquer l'acmè de l'utilisation du praefurnium.

On retrouve au S. du praefurnium une couche analogue à celle qui s'est déposée sur son sol, comme si l'on avait épandu sur une grande surface les cendres dues à son utilisation. C'est pendant la constitution de cette couche qu'ont été créées les installations reconnues plus au S. dans la galerie E. : on les jugera donc contemporaines, sinon de la création, du moins de la pleine période d'utilisation du praefurnium.

\section{- au S.-E. (dans le sondage 2) une pièce de service(?) et un sol.}

\section{A la différence du praefurnium, cette pièce (fig. 8) n'a été que très incomplètement dégagée.}

Seul le mur N. - ou mur V - a en effet èté clairement reconnu, sur une longueur de $2,40 \mathrm{~m}$ correspondant à la largeur de la galerie : à l'E. il disparait sous les fondations du mur E. du cloitre, tandis qu'à l'O. il se poursuit sous les fondations du stylobate du cloitre, très légères dans ce secteur.

Le mur est large d'une quarantaine de $\mathrm{cm}$ et conservé sur une hauteur moyenne de $0,60 \mathrm{~m}$, soit trois assises de moellons et blocs de remploi sommairement jointoyés et fondés (sans ressaut de fondation) dans la couche cendreuse 5a. Sur sa face N. il a été renforcé sur une épaisseur d'une vingtaine de $\mathrm{cm}$ par une série de moellons liés à l'argile fondés à $0.20 \mathrm{~m}$ au-dessus de la base du mur primitif, soit au sommet de la couche 5a (cf. fig. 23). Il s'agit très vraisemblablement d'une réfection dont les témoins ne sont bien conservés qu'à l'O., mais dont on ne peut douter qu'elle avait affecté le mur en entier. La face $\mathrm{S}$. est enduite du même béton de tuileaux qui recouvre le sol.

La limite S. de la pièce est sans doute à chercher au-dessous d'un mur du haut Moyen-Age (infra, p. 132), le mur VI qu'il a été impossible de démonter dans les délais impartis à la fouille. La pièce aurait donc mesuré environ $2 \mathrm{~m}$ du N. au $S$. D'E. en $\mathrm{O}$. la dimension minimale, on l'a dit, est de $2,40 \mathrm{~m}$. Il est possible que le mur E. de cette pièce, comme celui du praefurnium, ait èté le mur E. du portique remployé; possible aussi que la mur XI installé sur le stylobate antique (infra, p. 125) s'il se poursuivait bien vers le N., ait fermé la pièce à l'O., mais, faute d'avoir pu faire les vérifications nécessaires, on ne peut en être sûr.

Le sol est constitué de deux niveaux superposés de béton de tuileaux séparés par une couche de moellons et de gros galets de $0,10 \mathrm{~m}$ d'èpaisseur : faut-il y voir la trace d'une réfection, ou un souci marqué d'assurer la protection du monument contre l'humidité ? Le soin apporté à sa construction tranche en tout cas sur le caractère assez négligé du mur V. qui a . il est vrai, certainement perdu son parement primitif au $\mathrm{N}$.

Le premier niveau de béton de tuileaux est une dalle épaisse d'une dizaine de $\mathrm{cm}$ construite à l'intérieur de la couche $5 \mathrm{a}$ à la cote $203,41 \mathrm{~m}$; le second, d'épaisseur égale. n'est que le support du sol proprement dit. constitué de briques qui ont toutes disparu. laissant pourtant leur empreinte dans l'enduit rose. Leurs dimensions étant exactement semblables à celles employées pour les fondations du mur II du praefurnium $(30 \times 45 \mathrm{~cm})$, on pourrait songer, compte tenu de leur épaisseur, à restituer le sol de la pièce aux alentours de la cote $203.62 \mathrm{~m}$.

La fouille n'a pas permis de deviner les fonctions de cette pièce à la structure plus complexe que ne l'indique cette description rapide.

On trouve au S.-E. un bloc en grand appareil (pris dans le beton de la première dalle et qui culmine au niveau de la seconde) et il est possible qu'un bloc analogue, maintenant disparu, ait existé au N.-E. au long du mur $\mathrm{V}$ où le béton est absent sur une surface rectangulaire de $1 \mathrm{~m} \times 0.60 \mathrm{~m}(17)$. Peut-être ce ou ces blocs servaient-ils à aider au support d'une éventuelle couverture?

(17) C'est l'absence du béton de la dalle infërieure dans cette zone qui a permis de vérifier qu'elle repose sur la partie inférieure de la couche 5 a car la fouille a été arrètée ailleurs au niveau de la première dalle de béton. 


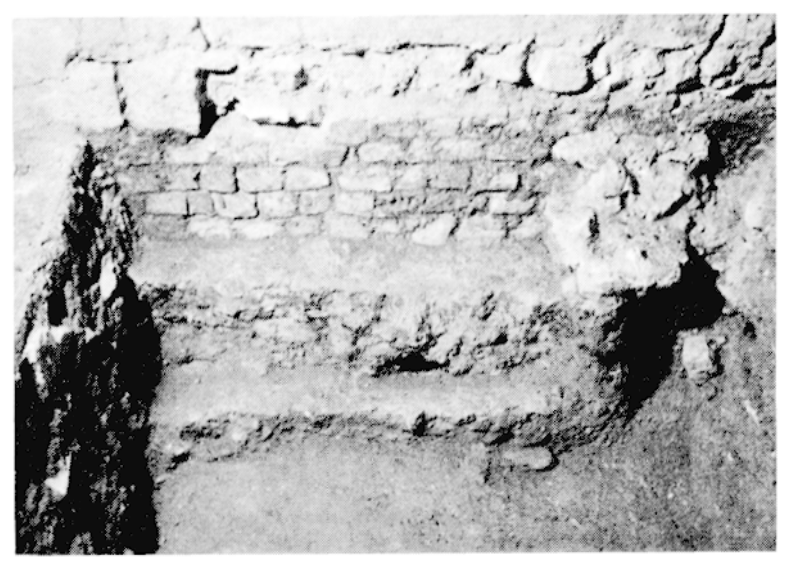

Fig. 11. - Sondage 4.

Mur S. du cloitre vu du N.

Le mur médiéval a été appuyé sur un mur (antique?) en petit appareil; à d., arrachement du mur perpendiculaire XII.

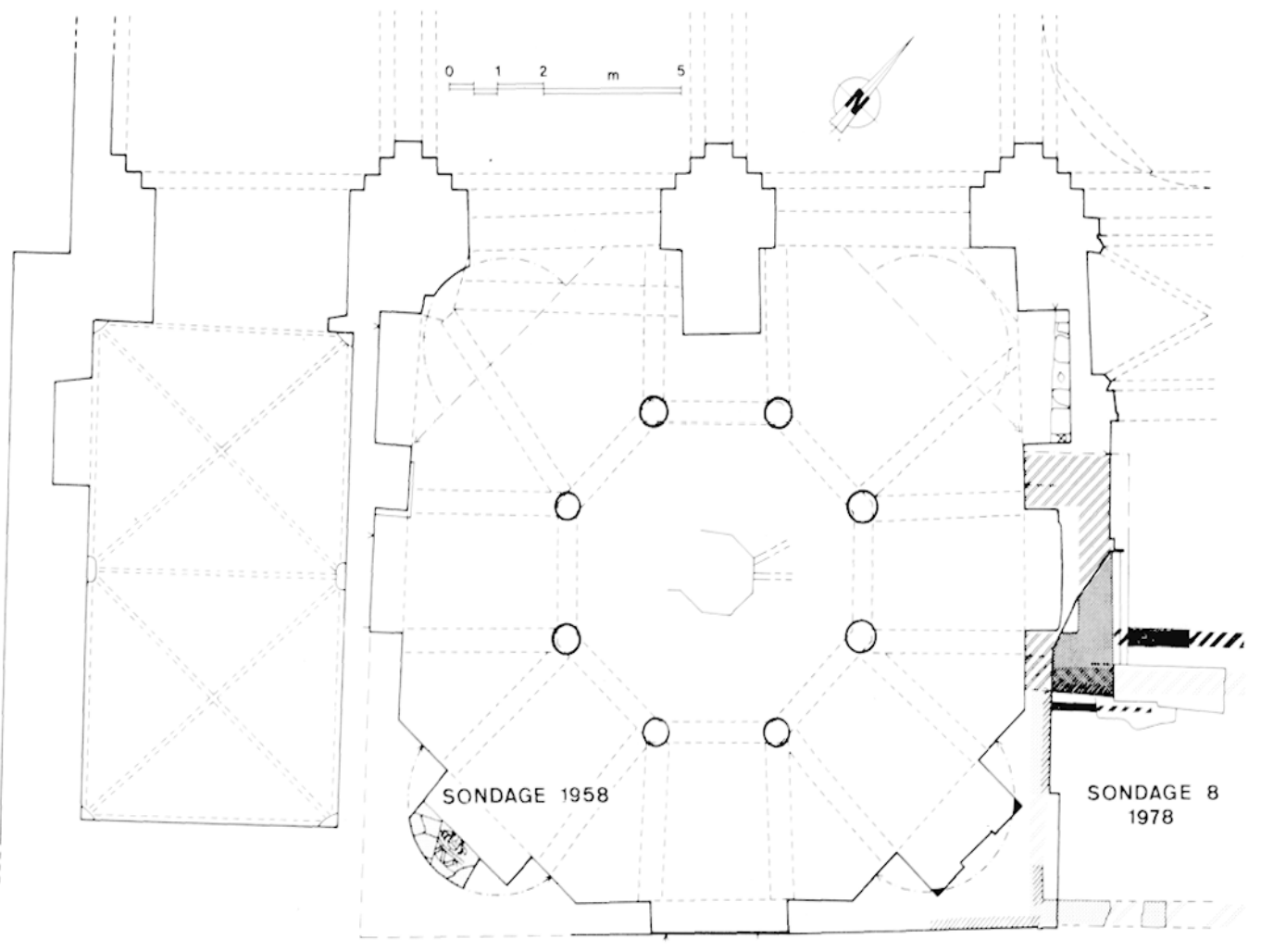

Fig. 12. - Plan du baptistère.

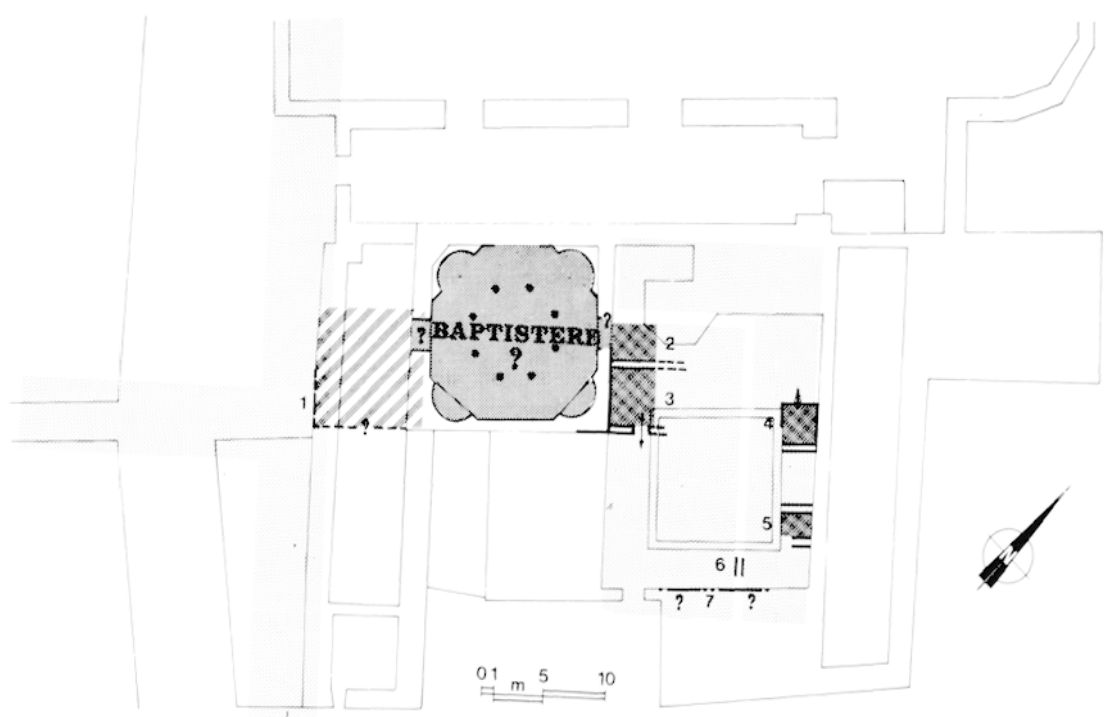

Fig. 13. - Schèma de situation à la fin de l'Antiquité (en grisé clair, l'état du Haut-Empire). L'existence et le plan du baptistère sont hypothétiques.

1: mur en petit appareil construit sur le cardo (fouille de 1958): 2 : annexe N.-E. du baptistère (?) (sol bétonné et caniveau); 3 : annexe S.-E.?; 4 : praefurnium; 5 : pièce de service (?) S.-E.: 6 : mur XI sur le stylobate; 7 : mur antique S.? 
Au S. de cette pièce on a dégagé un alignement de gros galets et de moellons sensiblement parallèle à l'axe du portique, qui forme comme la bordure d'une sorte de trottoir haut d'une quinzaine de $\mathrm{cm}$ : les galets séparent en effet une zone déprimée à l'O. d'une zone plus haute à l'E., constituée dans les deux cas d'une argile jaune très compacte. Sans doute s'agit-il d'un sol; non fouillé à l'O., il repose à l'E. sur la couche cendreuse $5 \mathrm{~d}$, et bien qu'il n'ait livré aucun matériel datable, on ne doutera guère, à examiner ses cotes, qu'il a probablement été utilisé en mème temps que la pièce qui lui fait suite au $\mathbf{N}$.

Par leur implantation $0,50 \mathrm{~m}$ environ au-dessus du niveau du portique ces constructions témoignent elles aussi de sa désaffectation.

\section{Les réoccupations de fortune}

\section{- Un mur construit sur le stylobate au S. (sondage 3)}

Plus encore que ceux qui ont été précédemment décrits ce mur - le mur XI - est une construction sommaire dont seul le parement E. est conservé (fig. 4).

Ce parement est constitué d'une série de blocs liés à l'argile élevés à la verticale de la face E. du stylobate (cf. fig. 24) : quatre assises au plus sont conservées pour une hauteur de $0,35 \mathrm{~m}$. Sans doute faut-il restituer à l'O., à l'autre extrémité du bloc ou légèrement en retrait, un parement identique: entre les deux parements, le cœur du mur était rempli de terre et de pierraille.

Ce mur fournit un nouvel indice de l'abandon du portique dont il condamne l'accès; pourtant, était-il un simple muret barrant le passage dans l'entrecolonnement ? ou une construction plus ample édifièe sur un stylobate déjà dépouillé de ses colonnes? Les données de la fouille interdisent de répondre à ces questions (18).

\section{- Une réoccupation très fruste au $N$. (sondage 9)}

L'unique sondage qu'il a été possible de pratiquer dans la galerie $\mathrm{N}$. a une extension très réduite; du moins a-t-il permis de reconnaitre à la côte moyenne 203,31 m un niveau d'occupation (cf. fig. 29).

C'est un sol constitué d'une couche argileuse jaune épaisse d'une quinzaine de $\mathrm{cm}$ à l'intérieur de laquelle ont été creusées deux rigoles perpendiculaires larges d'une dizaine de $\mathrm{cm}$ et profondes d'autant, dont seules les extrémités $\mathrm{N}$. et $\mathrm{O}$. étaient visibles sur la surface du sondage. Peut-être ces rainures étaient-elles destinées à recevoir des cloisons de bois?

Le niveau argileux s'est révélé stérile, ou presque. La couche sous-jacente (un remblai reposant sur les fondations des dalles et du stylobates déposés) a livré en revanche de la céramique antique tardive (couche 5b, sond. 9, fig. 30 et 40 ).

\section{b. A l'O. et peut-être au S. d'importants bâtiments.}

\section{Les constructions de l'O. (sondages 7 et 8 )}

Dans la galerie $\mathrm{O}$. la fouille a permis de reconnaitre trois murs fondés sur le dallage primitif qui appartiennent à un ensemble complexe de bâtiments qu'on n'a pu qu'entrevoir.

Un premier mur - le mur XX - suit grossièrement l'orientation N.-S. du dallage. On l'a reconnu à la fois dans le sondage 7 et dans le sondage 8 en deux points distants de $2 \mathrm{~m}$.

Bien que les deux portions dégagées ne soient pas exactement alignées (la partie $S$. est en retrait vers l'O. d'une dizaine de $\mathrm{cm}$ par rapport au tracé $\mathrm{N}$.) et bien que leur parement ne soit pas non plus absolument identique, on ne doutera guère qu'elles appartiennent à un mème bâtiment, sinon à un mème mur. C'est cette dernière interprétation - la plus vraisemblable - qu'on adoptera pour simplifier.

Au S. la partie dégagée dans le sondage 7 est longue de $0,70 \mathrm{~m}$. Elle sert de fondation au mur $\mathrm{E}$. du baptistère, de sorte que seule sa face $E$. a pu ètre étudièe: l'èlévation en outre est partiellement masquée par les fondations d'un mur très récent doublant le mur du baptistère (19) et n'est visible que sur une hauteur de $1.10 \mathrm{~m}$ (cf. fig. 22).

(18) Le mur est en effet détruit trop au $\mathrm{N}$. de la colonne disparue du stylobate pour qu'on puisse affirmer qu'il ètait limité au seul entrecolonnement.

(19) On a trouve des gravats provenant de la destruction d'un sol en ciment à la base de sa tranchée de fondation. 
La surface mise au jour est cependant suffisante pour étudier le parement du mur directement fondé sur le dallage du HautEmpire conservé dans cette zone. Les fondations, hautes de $0,30 \mathrm{~m}$, se composent de trois assises de moellons. Au-dessus d'un ressaut de fondation de $0,10 \mathrm{~m}$ environ commence l'élévation proprement dite (également composée de moellons relativement bien calibrés liés au mortier) qui présente deux particularités : d'une part un léger ressaut de 3 à $4 \mathrm{~cm}, 0,20 \mathrm{~m}$ au-dessus du ressaut de fondation; d'autre part un changement de nature du mortier à la cote $203.91 \mathrm{~m}$, au long d'une ligne horizontale qui marque aussi la limite entre la partie inférieure du mur, qui porte un enduit rose de béton de tuileaux, et la partie supérieure qui n'est pas enduite.

Dans le sondage 8 la partie $\mathrm{N}$ du mur, qui sert également de fondation au mur $\mathrm{E}$ du baptistère. a été dégagée sur une plus grande longueur - 1,50 $\mathrm{m}$ - et l'absence dans cette zone du mur moderne doublant celui du baptistère permet d'ètudier son élévation sur une hauteur de $2 \mathrm{~m}$ environ (cf. fig. 22).

Cette fois, le mur est fondé, non sur les dalles disparues, mais directement sur le hérisson qui les portait, et seule une série de moellons de grande taille marque la base du mur: au-dessus, l’élévation est assez comparable à celle qui a été décrite plus au $\mathrm{S}$., à cette différence près qu'on ne rencontre ni ressaut $0.20 \mathrm{~m}$ au-dessus des fondations, ni trace d'enduit (mais celui-ci a pu disparaitre): en revanche, on note à la cote $203,91 \mathrm{~m}$ soit exactement au-dessous d'un trou (de boulin?) situé $1 \mathrm{~m}$ au-dessus du niveau du dallage antique. le mème changement de nature du mortier qui a déjà été signalé au $S$.

On ignore quelle est la limite septentrionale de ce mur, qui est masquée par la niche à fond plat de la face E. du baptistère (infra, p. 138-140) au-dessous de laquelle on n'a pu pratiquer aucun sondage. Au S. on est sûr seulement qu'il ne se poursuit pas dans le sondage 6 où la fouille a révélé que le mur du cloître, comme le mur moderne qui le double, sont peu profondément fondés (à la cote 203,91) sur une couche de remblai (cf. fig. 22). Dans ces conditions, il est possible, mais non certain, que le mur antique s'arrête avec l'angle S.-E. du baptistère qui est fondé sur lui.

C'est en ce point en tout cas qu'a été reconnu un second mur - le mur XVI - perpendiculaire au précédent, dont l'examen a été rendu difficile à cause à la fois de l'exiguité du sondage et de l'existence de vestiges (les fondations du stylobate primitif du cloître, infra, p. 136) qui le masquent partiellement et que l'on voulait conserver.

Il semble cependant que ce mur, large de $0,50 \mathrm{~m}$, avait une longueur d'au moins $3.75 \mathrm{~m}$ correspondant à la largeur de la galerie : à l'E. en effet les fondations soignées du stylobate actuel du cloitre reposent à la cote $203.91 \mathrm{~m}$ (qui est celle de l'écrêtement du reste du mur à l'O.) sur une série de moellons appartenant selon toute apparence au mur XVI qui se poursuivait donc vers l'E. sous la cour du cloitre.

A l'O. le mur est collé contre le mur XX auquel il est apparenté par sa technique de construction : mêmes fondations sur les dalles (ou le hérisson sous-jacent là où elles avaient disparu) faites de trois assises de moellons liées par un mortier assez pauvre; mème cote de fondation, avec toutefois un ressaut un peu plus important $(0.30 \mathrm{~m})$; enfin sans doute mème élévation, si l'on s'en rapporte du moins à la face $S$. du mur (la face $N$. a perdu son parement).

On a tout lieu de croire qu'une porte perçait ce mur $2.60 \mathrm{~m}$ à l'E. du mur XX. sous l'emplacement du stylobate primitif du cloitre dont le présence a beaucoup gèné la recherche. Il est exclu en effet d'attribuer aux fondations très superficielles du stylobate primitif (à la cote $204.31 \mathrm{~m}$, alors que celle de l'écrêtement du mur XVI est à $203.91 \mathrm{~m}$ ) la disparition du mur à l'O. de cette construction; d'ailleurs la rupture n'est nullement accidentelle, mais marquée par des moellons de grande taille qui conviennent bien à un parement. Un sondage très exigu au droit du stylobate primitif a permis de reconnaitre au moins trois assises de moellons: si les deux plus éleveees sont bien à l'aplomb, la troisième au contraire est en saillie vers l'E. et disparait sous la berme du sondage : sans doute marque-t-elle à la cote $203.61 \mathrm{~m}$ le seuil d'une porte dont la largeur serait au plus d'l $\mathrm{m}$ si, comme nous le pensons, on retrouve bien l'élévation du mur sous le stylobate actuel du cloitre.

A $4,20 \mathrm{~m}$ au $\mathrm{N}$. du mur XVI a été reconnu un troisième mur, XVII, sensiblement parallèle au précédent, qui ferme au N. l'espace délimité par les murs XVI et XX.

On s'intéressera pour l'instant à la seule face $S$. de ce mur, qui n'est visible que sur une hauteur maximale de $1,80 \mathrm{~m}$ et une longueur de $1 \mathrm{~m}$ : il disparait en effet à l'E. sous le parement hétéroclite d'un puissant mur de renfort médiéval (infra, p. 139) et a été écrêté en élévation pour laisser place aux fondations en grand appareil de la niche à fond plat du mur E. du baptistère (infra. p. 139).

Le peu qui subsiste est cependant suffisant pour juger qu'il s'agit d'une construction très comparable aux précédentes, appuyée comme elles - sans ressaut de fondation - sur le hérisson supportant le daliage du Haut-Empire et constituée de moellons liés au mortier. La base du mur, sur une hauteur de $0.50 \mathrm{~m}$ environ, est revétue dun enduit rose de béton de tuileaux.

Le reste de lèlévation est plus original : tandis que la partie inférieure, jusquà la cote 203,91 m, est collée contre le mur XX, la partie supérieure est liée à lui (fig. 9). Plutòt qu'un simple repentir, c'est sans doute la trace d'une véritable rèfection, qui se situe. on le notera, à une cote assez remarquable : c'est celle de l'écrêtement du mur XVI, celle aussi du trou (de boulin ?) et du changement de nature du mortier dans le mur XX voisin.

A $0.50 \mathrm{~m}$ au S. du mur et parallelement à lui court un caniveau large de $0.15 \mathrm{~m}$ et profond de $0,20 \mathrm{~m}$ dont le passage sous le mur XX est couvert par une grosse pierre analogue à celle des fondations de ce mur. Sa localisation invite à penser qu'il est 
contemporain de la création des murs XVII et XX. La facture de ce caniveau (ou de ce petit égout ?) est soignée : il est protégé par un enduit hydraulique, et entièrement couvert par des briques de $30 \times 47 \times 8 \mathrm{~cm}$ frappées de la marque MVM (fig. 42) qui sont prises dans un mortier peu résistant. Il sert à drainer l'eau collectée à l'O. du mur XX; il est en effet en pente marquée en direction de l'E. et s'enfonce rapidement au-dessous du niveau du sol du Haut-Empire qui est le sien au voisinage du mur XX : sa construction a été rendue possible par la dépose partielle des dalles dans cette zone.

Il est sûr que le niveau du sol à l'intérieur de l'espace limité par les murs XVI, XVII et XX est audessus du sol du Haut-Empire. La cote de la porte ouverte dans le mur XVI - 203,61 m - inviterait à une restitution assez haute, mais il est possible aussi que le seuil ait été légèrement surélevé par rapport au sol qu'on placerait volontiers aux environs de $203,31 / 203,41 \mathrm{~m}$ si l'on s'avise que cette cote est celle d'un niveau cendreux qui a pu servir de sol (comme dans la galerie $E$. et à un niveau d'ailleurs très comparable). Les multiples remaniements qui ont affecté cette partie du sondage 8 n'ont pas permis de fouiller sur une surface suffisante ce niveau; au moins retiendra-t-on qu'il ne contenait que de la céramique antique tardive (sommet de la couche 3 b, sond. 8, fig. 30).

$\mathrm{Au}$ N. du mur XVII en revanche le niveau est certainement plus haut.

On a en effet reconnu dans cette zone à la cote $203.91 \mathrm{~m}$ un sol fait d'un béton de tuileaux reposant par l'intermédiaire d'un empierrement épals de $0.20 \mathrm{~m}$ sur un remblai de près de $1 \mathrm{~m}$ qui recouvrait les dalles antiques (cf. fig. 28).

Ce niveau a été reconnu sur une surface de $4 \mathrm{~m}^{2}$ seulement. Ses limites $\mathrm{N}$. et E. Sont inconnues: à l'O. il a été tranché par les fondations de la niche à fond plat à l'E. du baptistère et l'on peut seulement supposer que le mur XX. s'il se poursuivait bien vers le $\mathrm{N}$. sous lc mur du baptistère, en marquait la limite. $\Lambda \mathrm{u}$ S. enfin le sol bute contre un mur au parement de moellons dont l'élévation conservée sur une hauteur de $0,60 \mathrm{~m}$ est largement masquée par un enduit rose. Bien que la présence du mur tardif XVIII déjà signalé empèche toute vérification, on tient là, sans doute, le parement $\mathrm{N}$. du mur XVII dont on a déjà décrit la face $\mathrm{S}$. : si la restitution est exacte, ce mur aurait une largeur de $0.60 \mathrm{~m}$.

A $0.30 \mathrm{~m}$ au N. du mur XVII et parallèlement à lui court un caniveau large de $0.30 \mathrm{~m}$ et profond de $0.20 \mathrm{~m}$ revêtu d'un enduit hydraulique lissé (fig. 10). La construction est soignée, et pour éviter tout effondrement le fond du caniveau est supporté par un massif de blocage qui pourrait servir aussi à renforcer le parement du mur XVII (cf. fig. 28). Ce caniveau, qui est en légère pente en direction de l'E., ne porte aucune couverture : doit-on supposer que, si l'espace au S. du mur était couvert, il servait à recueillir l'eau de la toiture ? ou qu'il était à l'usage exclusif de l'espace (ouvert ou couvert ?) qu'il dessert ?

Un effondrement dủ à des infiltrations a troublé la couche de remblai au-dessous du sol: on notera seulement qu'elle se caractérise elle aussi par la présence de céramique antique tardive (couche 4, sond. 8, fig. 30 et 39 ).

On entrevoit donc à date basse, sur l'emplacement de la galerie 0 . du cloitre, l'existence de deux ensembles accolés au mur XX, qui limite lui-même un espace de destination inconnue (il aurait fallu pour préciser sa nature fouiller le baptistère). L'un au S. peut être une salle couverte qui avait une entrée au S. et dont le sol serait à placer aux environs de $203,41 \mathrm{~m}$; l'autre au $\mathrm{N}$. est surélevé de $0,50 \mathrm{~m}$ par rapport au précédent. C'est assurément dans cette zone que l'abandon et la transformation du monument du HautEmpire sont les plus impressionnants.

La réalité est plus complexe que ne l'indique cette description. A l'E. de la fouille dans le sondage 8 on a en effet retrouvé un moignon de mur - XXII - reposant directement sur les dalles romaines, qui est englobé au $\mathrm{N}$. dans le parement du mur médiéval XVIII déjà signalé et à l'E. dans un pilastre de béton très récent: il est trop médiocrement conservé sur une longueur et une hauteur de $0.50 \mathrm{~m}$ pour qu'on puisse l'étudier vraiment : s'agit-il d'un mur antique collé contre le mur XVII pour le renforcer? ou encore d'un fragment du parement éboulé du mur XVII qui aurait été remployé dans la construction hâtive du mur XVIII ? On ne sait.

\section{Un mur au S. ? (Sondages 3 et 4)}

A la base de l'élévation très remaniée du mur S. du cloitre (que l'on étudiera plus longuement infra, p. 136 et 138) on trouve dans le secteur oriental une portion de mur dont la facture est assez comparable à celle des murs reconnus dans la galerie 0 . (cf. fig. 17).

Le parement est bien constitué d'un petit appareil cubique layé en assises régulières et la construction s'appuie sur le dallage (fig. 11): on la rapprocherait sans hésiter des autres murs examinés jusqu ici si l'on ne trouvait à la base du mur des fondations larges de $0.20 \mathrm{~m}$ et profondes de $1.20 \mathrm{~m}$ qui font défaut ailleurs : faut-il penser que l'on a utilisé ici une technique différente? ou songer à un chemisage médiéval de la base du mur masquant une élévation originelle identique à celle que l'on trouve ailleurs ? ou encore à une construction tardive remployant des matériaux antiques? On ne sait.

Le parallèle est trop vague pour autoriser plus qu'une simple hypothèse : il a seulement $p u$ y avoir dans cette zone durant l'Antiquité tardive un monument dont l'ampleur et la destination nous échappent de toute manière. 


\section{INTERPRÉTATION}

Il est sans doute téméraire de proposer une interprétation globale pour des trouvailles si diverses et si dispersées, surtout en l'absence de couches archéologiques vraiment scellées, donc sans datations sûres, que l'imprécision et la chronologie des céramiques sigillées tardives rendrait d'ailleurs illusoires.

Deux faits nous paraissent cependant suffisamment assurés pour aider à une restitution.

Le premier est la désaffectation presque totale des installations du Haut-Empire, qui aurait touché non seulement la cour à portique, mais aussi le cardo voisin si l'on en croit les résultats d'un sondage de 1958.

L'emplacement exact de ce sondage est inconnu, mais le rapport qui en a été publié précise qu'on y a retrouvé un mur tardif (20) servant de fondation au " mur médiéval à bossages " qui s'étend au $\mathrm{S}$. de la porte de la cathédrale romane, et le contexte montre que c'est dans la partie $\mathrm{S}$. de ce mur qu'il faut le situer (21) : il est donc possible de placer à $23 \mathrm{~m}$ environ à l'O. du mur XX et sensiblement parallèle à lui (22) un nouveau mur qui lui ressemble par bien des traits : mêmes fondations, ici sur la cour, là sur le cardo sans doute rétréci pour l'occasion (23), mème appareil en moellons, mème destin aussi, puisque les deux murs ont servi de fondations à des constructions médiévales du groupe épiscopal, ce qui prouve qu'ils sont restés en usage - ou au moins visibles très longtemps. Il faut donc songer à une réoccupation de grande ampleur dans toute la zone 0 ., d'autant que ce nouveau mur n'était pas isolè (24).

Partout sur le site apparaissent donc presque simultanément des bâtiments qui remploient très sélectivement (surtout au $\mathrm{N}$. et à l'O.) non seulement des matériaux, mais aussi des pans entiers des monuments préexistants, comme le mur extérieur du portique, le stylobate (qui porte le mur XI) ou même l'alignement du cardo.

L'absence de sondages sur la plus grande partie de la galerie $\mathbf{N}$. et dans la cour du cloître empêchent sans doute de lire le plan d'ensemble de la réoccupation et de comprendre l'articulation de ses différents éléments; du moins est-il sûr qu'à l'E. comme à l'O. on est en présence de réalisations importantes par l'espace qu'elles couvrent et la relative complexité de leur organisation. L'impression prévaut alors que la réoccupation, loin d'être le fait du hasard, répond au contraire à un plan cohérent et ambitieux. C'est le second point qui peut aider à notre interprétation.

On s'étonnera peut-être de nous voir songer pour les constructions de la Basse-Antiquité à un programme architectural d'envergure : sur le site, le sol qu'on a cru reconnaitre un peu partout aux alentours de la cote $203,41 \mathrm{~m}$ a bien pauvre allure - de l'argile et de la cendre au lieu des dalles du HautEmpire; de même, les traces d'occupation que l'on trouve à proximité des bâtiments sont aussi très frustes : des trous de poteaux au N. et deux foyers au S.-E.

Le premier foyer est installé à la cote 203,61 m au-dessus du « trottoir » au S. de la seconde pièce de service de la galerie E.: le second, à la cote $203,21 \mathrm{~m}$, au-dessus d'un remblai adossé à l'E. au mur XI : cernés de galets ou de matériaux de remploi (dont un fragment de meule pour le second foyer) ils contiennent, mêlées aux cendres, de nombreuses coquilles d'huitres et de la céramique sigillée estampée grise en abondance (couche 5 a, sond. 2 ; couche $5 \mathrm{~d}$, sond. 3 ; fig. 30 et 33-34) qui fournit une nouvelle indication pour dater le sol sur lequel ils ont été aménagés. Mais il n’y a pas lieu de s'étonner de la médiocrité de ces restes : ils avoisinent des pièces de service.

La recherche sans aucun doute s'en est tenue aux communs, et seule la fouille du bâtiment qu'ils desservait permettrait de juger de la qualité et de la richesse éventuelles des constructions de l'antiquité

(20) F. Benoit. loc. cil., p. 416 le date "du Haut Moyen-Age "; sa facture le rapproche pourtant si ètroitement des murs étudiès jusqu ici qu'on le jugera plutôt de la Basse-Antiquité: la différence est mince, et tient sans doute au flou - si commode - du vocabulaire relatif aux dark ages.

(21) F. Benoit. ibid., signale que c'est sur le mur de la Basse-Antiquité qu'" est assis à fleur de terre le mur à bossages d'un alignement légèrement différent (saillie de $0.40 \mathrm{~m}$ au S.) ". L'appréciation de cette divergence d'alignement suppose que le sondage se situe dans la partie méridionale du mur à bossages, comme nous l'a dailleurs confirmé $M$. R. Ambard, alors chargé de la fouille.

(22) Le mur à bossages sous lequel a été retrouvé le mur de la Basse-Antiquité est en effet à peu près parallèle au mur $E$. du baptistère auquel le mur XX sert de fondation.

(23) Le retrécissement du cardo est certain. puisque la largeur de la voie reconnue en 1958 était limitée à $4.50 \mathrm{~m}$ par le mur tardif construit sur elle, alors que le cardo mesure $5.75 \mathrm{~m}$ de large plus au S., rue P.-Bert: F. Benoit, ibid., p. 416 et n. 5 .

(24) F. Benoit. ibid., p. 417, signale que le mur " fait partie d'un ensemble de constructions médiévales rasées au niveau du sol. à $1.40 \mathrm{~m}$ et $2 \mathrm{~m}$ à I'O." 
tardive. On ne peut pour l'instant qu'entrevoir l'existence d'un " étage noble " au-dessus des communs, à la fois au N.-E. avec la - ou les - pièce(s) chauffée(s) par le praefurnium qu'il a été impossible de fouiller, et au N.-O. avec l'espace à la finition très soignée qu'on trouve au $\mathrm{N}$. du mur XVII; mais le reste nous échappe, qu'il faut imaginer plus au $\mathrm{N}$. et l'O.

Il est bien difficile avec si peu d'éléments de définir la fonction de ces installations assurément importantes, surtout à l'O. où se multiplient les murs, au-dessous et à proximité du baptistère; mais le seul nom de ce bâtiment n'est-il pas un indice?

On a souvent observé en effet que sous le plan actuel du baptistère, qui date dans ses grandes lignes du Moyen-Age. transparait un état plus ancien, dans lequel on trouve, aux angles, des niches semi-circulaires à la place des niches rectangulaires actuelles.

Cette restitution se fonde généralement sur le seul fragment de mosaique découvert en 1958 dans la niche S.-0. (25) qui permet de lui rendre un tracé originel semi-circulaire, mais un examen attentif permet de trouver d'autres indices pour les niches N.-O. et S.-E. : la première se reconnait à un élément de cul-de-four conservé dans l'élévation médiévale, tandis que deux blocs obliques placés au ras du sol dans les angles de la seconde pourraient être les seuls témoins conservés de son arrondi initial (fig. 12).

Ayant ainsi restitue trois niches semi-circulaires sur quatre, on retrouve presque entièrement le plan de tant de baptistères antiques, comme celui de Marseille, avec lequel les ressemblances sont étroites (26); en son centre sinscrit bien la piscine octogonale fouillée pendant l'entre-deux guerres (27), qu'on imaginerait plus difficilement dans un bâtiment médiéval. Si l'on ajoute que nos fouilles ont révélé qu'à la base des murs médiévaux se trouvent, non des fondations, mais une èlévation antique, comment ne pas voir dans le baptistère de Saint-Sauveur une création de la Basse-Antiquité ?

Il est clair que la construction d'un tel monument suffirait à remplir le plan ambitieux qu'on a cru discerner à travers les réoccupations de l'antiquité tardive. Placé à peu près à égale distance du cardo et du stylobate, et adossé au mur N. restitué du portique (supra, p. 118), il couvrirait avec les annexes reconnues de l'E. et supposées à l'O. (constructions sur le cardo (?)) une surface déjà considérable (fig. 13); encore n'est-ce là qu'une partie d'un programme beaucoup plus important, car l'on doit supposer que l'édification d'une cathédrale et sans doute d'une domus épiscopale a accompagné celle du baptistère: l'ossature conservée du portique pourrait avoir servi à articuler cet ensemble complexe (28).

On a récemment proposé de placer au $V^{e}$ siècle la création de ce groupe épiscopal (29) sur les ruines duquel ont été reconstruits au XII siècle la cathédrale romane et ses annexes (infra, p. 134-138) et la datation suggérée par notre fouille semble bien apporter une confirmation de cette hypothèse.

Deux raisons pourtant doivent nous interdire d'identifier formellement et sans restriction les vestiges retrouvés avec ceux du baptistère antique et de ses annexes.

La première est de principe : rien de définitif ne peut être avancé avant la fouille de l'intérieur même du baptistère actuel. La seconde, aussi dirimante, tient aux données de la fouille, qui font apparaitre une difficulté réelle d'identification : le niveau actuel du baptistère - environ $204,13 \mathrm{~m}$ - , s'il est bien celui du Moyen-Age, a toute chance pourtant d'être très voisin du niveau originel (30); or, il est près de $0,75 \mathrm{~m}$ audessus de la plus grande partie du niveau de la Basse-Antiquité reconnu à son voisinage (cf. fig. 27).

Sans doute la nature des installations fouillèes alentour - pièces et cour de service - peut-elle expliquer qu'elles se placent à un niveau inférieur à celui du bâtiment principal ; peut-être aussi a-t-on voulu accentuer le caractère monumental du baptistère en

(25) F. Benoit, ibid., p. 416 et fig. 7

(26) Pour ce monument la publication essentielle est celle de F. Roustan. La Major et le premier baptistire de Marseille. Marseille. 1905: on la complètera utilement par la mise au point récente de X. Barral i Altet - D. Drocourt. Le buptistere paléochrétien de Marseille, dans Archéologia, 73. aoút 1974, p. 6-19: voir notamment la fig. 7. p. 13 pour le plan de ce monument notablement plus ample cependant que celui d'Aix : il sinscrit dans un carré de $23 \mathrm{~m}$ de cóté (contre $15 \mathrm{~m}$ environ à Aix).

(27) J. Formigè. Chroniques, dans B.S.N.A.F. 1927, p. 27 et 146-148: 1928, p. 315.

(28) On imaginerait volontiers par exemple la cathédrale placée. comme aujourd hui, au $\mathrm{N}$. du baptistere. dans une zone ou a dailleurs longtemps subsiste un édifice antique ( la "Sainte Chapelle ", ou " oratoire de S. Maximin " - l" oratoire du Sauveur » du . Woyen-Age - ) détruit en 1808: dans ce cas. le mur $\mathrm{N}$. restitué du portique marquerait la césure entre ces deux éléments majeurs du groupe épiscopal. Les indices sont cependant si fragiles que c'est là plus une supposition qu'une hypothese.

(29) P.A. Février, loc. cit., p. 56.

(30) La mosaique de la niche S.-O. (peut-être surélevée. comme les niches du baptistère antique de Fréjus) est à la cote $204.31 \mathrm{~m}$. soit une vingtaine de $\mathrm{cm}$ seulement au-dessus du dallage du baptistère médiéval : cf. aussi $\mathrm{F}$. Benoit. loc. cil., p. 416 , qui évalue la dénivellation a $0.25 \mathrm{~m}$. 
l'exhaussant par rapport à l'espace qui l'entoure et la rue qui le longe; il reste pourtant que son niveau est plus proche de celui d'un puissant remblai dont nous allons bientôt retrouver les traces que des niveaux étudiés jusqu'ici, et cette observation ouvre le champ à d'autres hypothèses.

On pourrait par exemple supposer que l'installation du baptistère à niches semi-circulaires de SaintSauveur a été due, non pas à une création originale, mais à la transformation (aussi ample qu'on voudra) d'un monument préexistant, dont la fonction - civile ou religieuse ? - nous échappe.

Il est possible en effet d'interpréter les murs que nous avons retrouvés comme ceux de bâtiments qui auraient eu leur sol entre 203,41 et $203,91 \mathrm{~m}$, tandis que l'exhaussement à la cote $204,13 \mathrm{~m}$ serait à mettre au compte de leur remploi ou de leur réfection par l'Eglise au moment où l'on aurait porté le sol alentour au niveau 204,13/204,23 m comme nous allons bientôt le voir.

Les anomalies constatées dans l'élévation des murs XVII et XX (supra, p. 126) seraient les seuls témoins conservés de cette transformation des édifices de la Basse-Antiquité qui prendrait place pendant le premier Moyen-Age.

L'hypothèse pourra sembler gratuite, inutilement compliquée en tout cas quand tout - ou presque s'explique assez bien, on l'a vu, par la seule création d'un groupe épiscopal (ou à tout le moins d'un baptistère) sur le site dès la Basse-Antiquité.

Sans dissimuler notre préférence pour cette dernière solution (que divers indices mineurs, nous le verrons, permettent de conforter) nous croyons pourtant que la prudence commande de présenter aussi l'autre hypothèse tant que la fouille du baptistère n'aura pas permis de connaître précisément l'histoire de ce bâtiment.

\section{AU HAUT MOYEN-ÂGE : Ȧ PROXIMITÉ DU BAPTISTÉRE DES BÂTIMENTS ET UNE NÉCROPOLE}

Les vestiges de cette nouvelle phase d'occupation sont beaucoup plus superficiels. Leur création suppose la constitution d'un puissant remblai qu'il convient d'étudier en priorité.

\section{Une couche de destruction et un remblai}

Le niveau de l'antiquité tardive est effectivement partout recouvert par une couche relativement meuble qui contient en abondance les matériaux de démolition hétérogènes, moellons, marbre et mortier, qu'on attend dans une terre rapportée. Cependant, si l'on suit bien en stratigraphie la base de la couche, le sommet se laisse plus difficilement appréhender.

Le seul niveau dont on retrouve nettement trace sur l'ensemble des sondages se situe aux alentours de $204.41 \mathrm{~m}$. On peut être assuré qu'il s'agit bien d'un sol par la présence à sa surface, au N.-E. du sondage I, d'un foyer en forme de demi-cercle de $0,60 \mathrm{~m}$ de diamètre appuyé contre le mur $\mathrm{I}$, et entouré d'une couche de cendres de plusieurs mètres carrés de superficie, ou encore par le voile de mortier qui le recouvre dans les sondages 4 et 5 ; ailleurs, et notamment dans les sondages 3 et 7 , sa présence est documentée par des empierrements réguliers, des jonchées de cailloutis ou des dépôts de matériel de rebut (dont des fragments de canalisation en pierre) qui ont été établis ou déposés à sa surface. Des témoins conservés en des points aussi distants de la fouille prouvent suffisamment l'existence d'un aplanissement général du site autour de la cote $204.41 \mathrm{~m}$.

La question se pose pourtant de savoir s'il s'agit du seul nivellement quait connu la zone. Divers indices laissent penser que ce n'est peut-être pas le cas.

On pourrait songer par exemple à un premier exhaussement qui aurait porté le niveau du sol aux alentours de $203,91 \mathrm{~m}$ : c'est dans le sondage 2 la cote à laquelle on rencontre une mince pellicule d'argile presque partout présente au N. du mur VI, et c'est surtout dans le sondage 8 la cote, non seulement de l'arasement très soigné du mur XVI, mais aussi du changement de nature du mortier dans le mur XX et du début de la liaison du mur XVII avec le mur XX contre lequel sont seulement collées ses assises inférieures (supra, p. 126).

Pourtant, si l'on considère le sondage 1, c'est à un nouvel exhaussement qu'il faudrait songer, autour de la cote $204,13 \mathrm{~m}$ cette fois, à laquelle ont été écrêtés trois des murs du praefurnium, tandis que le mur remployé du portique était respecté: le bâtiment de service est d'ailleurs empli jusqu'à ce niveau par une couche de destruction et de remblai qui témoigne d'un arasement volontaire et soigné (cf. fig. 23). 
Tout serait clair si nous pouvions bien différencier les apports constituant ces niveaux. Or le remblai a partout le même aspect et les matériaux de remploi qui le composent - le marbre notamment - figurent également à tous les étages de la stratigraphie, au point qu'on peut douter par exemple que le niveau qu'on a cru entrevoir autour de $203.91 \mathrm{~m}$ soit aussi bien attesté qu'il le semblait de prime abord (31). Il serait vain dans ces conditions d'esquisser une subtile chronologie relative entre les différents comblements plus ou moins assurés et les installations qu'ils ont pu accueillir, et mieux vaut prendre le remblai comme un tout - ou presque.

A examiner le matériel, l'impression prévaut en effet que l'apport de terre sur le site a été subit et massif, portant le niveau, sinon d'un coup à la cote $204,41 \mathrm{~m}$ qui n'a peut-être été atteinte qu'après une période d'utilisation plus ou moins longue (32), du moins à une cote très voisine, autour de 204,13/ 204,28 m par exemple.

La masse de ce remblai, qui se chiffre par centaines de mètres cubes, suppose une modification profonde de la situation héritée de la Basse-Antiquité, que trahit également la quantité considérable de matériaux de démolition - les marbres de placage notamment - qui proviennent peut-être du dépouillement complet des bâtiments du Haut-Empire encore conservés. La datation de cette importante transformation est difficile à préciser.

Le gros de la céramique fournie par le remblai appartient encore sans aucun doute à l'antiquité tardive, mais quelques rares tessons de céramique commune grise semblent rappeller (ou annoncer ?) des types attestés aux $\mathrm{X}^{\mathrm{e}}$ - $\mathrm{XF}^{\mathrm{r}}$ siècles sur d'autres sites provençaux (couches 3 a et 4 a, sondages 3 et 7, fig. 30 et fig. 34 et 38) (33); pour adopter sans hésiter la chronologie basse suggérée par la céramique la plus récente. il faudrait sans doute que le remblai ait livré plus de fragments appartenant sùrement au Moyen-Age (mais peut-on toujours faire le départ dans la céramique commune grise entre les tessons du Bas-Empire et ceux du Haut Moyen-Age ?): il faudrait surtout que la fouille de sites médiévaux de haute époque ait démontré que les formes attestées aux $\mathrm{X}^{\mathrm{c}}-\mathrm{XI} \mathfrak{c}$ siècles appartiennent en propre à cette époque et ne sont pas dérivées de modèles d'un passé plus ou moins lointain (34).

Dans l'état actuel des connaissances céramologiques, mieux vaut prudemment se contenter d'une très large approximation : c'est pendant lę Haut Moyen-Age que le site a connu le second grand bouleversement de son histoire.

Selon qu'on aura choisi d'interpréter ou non comme un baptistère et ses annexes les monuments que nous avons retrouvés précédemment sur le site, on pourra rapporter le remblai à la transformation de ces bâtiments de la Basse-Antiquité en monuments chrétiens, ou seulement à une modification d'envergure du groupe épiscopal. La présence à la base de la stratigraphie d'une pierre portant un chrisme retrouvée dans le sondage 2 (fig. 14)(35) irait assez dans le sens de la dernière hypothèse.

\section{Des murs (Sondages $2 \mathrm{~S}$ et 3 )}

\section{Trois murs ont été reconnus dans l'angle S.-E. du cloître (murs VI, VII et X).}

Il s'agit de constructions à la fois puissantes (le mur X a 0,80 m d'épaisseur, les deux autres $0.65 \mathrm{~m}$ ) et frustes dans lesquelles abondent les matériaux de remploi (notamment des blocs de pierre de taille) sommairement liès à l'argile.

(31) La couche argileuse du sondage 2 peut nètre qu'un des multiples apports du remblai, et l'on n'a trouvé dans le sondage 8 aucun sol associé aux remaniements signalés supra: mais il est vrai que les couches ont été trés bouleversées dans cette zone. notamment par le "trou d'homme" liè à la construction du mur XVIII (infra. p. 139).

(32) Dans le sondage 3 par exemple la jonchée de cailloutis qui marque le niveau $204.41 \mathrm{~m}$ est au-dessus du mur $\mathrm{X}$ détruit : il est donc assuré qu'il y a eu, au moins dans cette zone. une constitution relativement lente du niveau définitif.

(33) Par exemple les fragments $n^{\alpha} 3153$ et 7415 . voisins des vases à fond " bombé " que l'on trouve dans les niveaux des $\mathrm{N}^{\mathrm{e}}-\mathrm{xl}^{\mathrm{e}}$ siècles des fouilles encore partiellement inédites de Cadrix (Var) et Cucuron (Vaucluse). On pourra se reporter sur ce point. quand la publication en sera parue. à la contribution de E. Boucharlat - M. Colardelle - M. Fixot - J.P. Pelletier, Eléments comparatifs de la production céramique du XF' siécle dans le bassin rhodanien, dans La céramique médievale en Méditerranée occidentale (I $X^{\prime \prime}-X V^{\prime \prime}$ s.), Colloque International du C.N.R.S.. Sophia-Antipolis. 11 . 15 septembre 1978.

Nous devons cette identification et ces renseignements (ainsi que ceux qui figurent à la $\mathrm{n}$. suivante) à J.-P. Pelletier.

(34) L'hypothèse n'est pas gratuite : les formes attestées à Saint-Sauveur rappellent seulement (ou préfigurent ?) celles qu'on rencontre aux $\mathrm{x}^{\mathrm{e}}-\mathrm{x} \mathrm{I}^{\mathrm{e}}$ siecles: peut-être sont-elles beaucoup plus anciennes?

(35) Bloc de pierre calcaire au dos irrégulier, sans doute un fragment d'architecture (linteau de fenêtre ?) provenant du sondage 2 N.. couche 4 ; $\mathrm{n}^{\circ}$ d'inventaire : 1436. L. : $0.33 \mathrm{~m}: \mathrm{H} .: 0.14 \mathrm{~m}:$ e. : $0.10 \mathrm{~m}$ : diamètre du cercle (ou plus probablement de la couronne de laurier ébauchée) entourant le chrisme : $0.11 \mathrm{~m}$. Lettres rehaussées au minium. On notera l'absence de l'oméga que l'on attend à d.. symétriquement à l'alpha. 
Les murs VI et VII sont liès entre eux, bien qu'ils soient fondés à des cotes diffèrentes $(203,81 \mathrm{~m}$ pour le mur VI, 204,11 m pour le mur VII): tous deux ont été tronqués, le mur VI par le contrefort des fondations du mur de la galerie E., le mur VII par la tranchée de fondation du mur de la galerie $\mathrm{S}$. Le mur X, sensiblement parallèle au mur VII et fondé presque à la même cote que lui $(204,15 \mathrm{~m})$, a connu le mème sort; au N., il se poursuit sous la cour du cloitre.

Il y a à peine $1 \mathrm{~m}$ de distance entre les murs VII et X, et l'on restituerait volontiers un couloir ou un escalier à cet emplacement s'il ne fallait reconnaitre que tout nous échappe des bâtiments auxquels appartenaient ces murs : on ne sait ni l'élévation que pouvaient supporter d'aussi médiocres constructions, ni la cote du sol qui leur était associé (peut-être a-t-il disparu avec le dernier aplanissement de la zone ?); encore moins peut-on proposer une datation ou une interprétation.

\section{Une nécropole (fig. 15)}

\section{Elle n'existe qu'au S.-E. du baptistère, dans les sondages 5 et 6.}

Six tombes ont été reconnues, très abîmées par la tranchée médièvale (infra, p. 139) qui traverse cette zone du N. au S. : aucune n'est intacte. Une seule est une inhumation en pleine terre; les autres sont constituees d'un coffrage (des dalles en calcaire épaisses de $0,10 \mathrm{~m}$ placées de chant) couvert par des dalles analogues disposées transversalement.

L'axe des tombes est E.-O., le corps reposant directement sur la terre, la tête à l'O. L'enfant déposé dans la tombe I a été inhumé l'avant-bras d. et la main sur l'abdomen, l'avant-bras g. sur les hanches et le pubis; des quatre autres squelettes (deux d'hommes et deux de femmes), trop mal conservès, on peut seulement dire qu'ils sont en position de décubitus dorsal. Deux des tombes, $n^{05} 2$ et 3 , ont connu une réoccupation. les ossements du sujet primitif étant alors disposés sans ordre aux pieds du deuxième corps. On n’a trouvé aucun matériel (mais toutes les sépultures ont été violées par le creusement de la tranchée médièvale, ce qui pourrait expliquer des disparitions).

Quatre des tombes en coffrage ont leur couverture à la cote 204/204,05 m: la cinquième, plus superficielle $(204.41 \mathrm{~m})$ et trop endommagée par la tranchée, n'a pas été fouillée. La sépulture en pleine terre voisine se situe sensiblement au mème niveau qu'elle (le crâne est à la cote $204,06 \mathrm{~m}$ ). Ces différences de niveau répondent-elles à une évolution chronologique ou traduisentelles, plus simplement, un changement d'habitude des fossoyeurs? On notera en tout cas qu'il n'y a aucune superposition de sépultures.

Les tombes se rattachent au type VI de la classification de S. Gagnière (type carolingien et roman) (36), et sans doute sont-elles assez tardives, antérieures pourtant à la fin du XII ${ }^{e}$ siècle, car rien ne permet de les mettre en relation avec le cloitre roman (ni leur cote, ni leur orientation, ni surtout le contexte ne s'y prêtent car l'on n'a retrouvé d'inhumations sous le cloitre nulle part ailleurs) et tout semble indiquer au contraire que c'est la proximité du baptistère - et au-delà du groupe épiscopal - qui a déterminé durant le premier Moyen-Age le développement de ce cimetière.

La datation des tombes s'accorde bien avec celle du remblai dans lequel elles ont été creusées; il est possible cependant que la coutume d'inhumer à Saint-Sauveur ait été beaucoup plus ancienne que ne le laissent supposer les sépultures fouillées.

F. Benoit a en effet retrouvé en 1958 au N. du cloitre un fragment, assurément déplacé, d'une inscription chrètienne qu'il date du vie siècle (37), et nous avons nous-mêmes recueilli dans les couches superficielles du sondage 5 un autre fragment (fig. 42 , $\mathrm{n}^{\circ} 4$ ), trop mutilé pour autoriser une restitution sûre, qui présente la facture des inscriptions chrétiennes antiques (infra, p. 154).

On n'attacherait qu'une importance réduite à ces pauvres restes šil n'existait sur le site une troisième inscription, beaucoup mieux conservée, qui a èté remployée par les bâtisseurs du XII siècle pour servir de support à la colonnade du cloitre : c'est le matériau, et non le texte, qui les a intéressés (ils ont scié le marbre pour le réutiliser), et l'on jugera par là qu'ils l'ont sans doute trouvé sur place (38). Or cette épitaphe est certainement celle d'un évêque aixois, qui pourrait ètre Basilius, titulaire du siège épiscopal autour des années 500 (39).

(36) On a adopté cette typologie classique. qu'il conviendrait pourtant de nuancer à la lumière des découvertes récentes : $\mathbf{S}$. Gagnière. Les sépultures a inhumation du II" au XI"' siècle dans la basse vallee du Rhöne - essai de chronologie lypologique, dans Cahiers rhodaniens, $12.1965=$ tirè-à-part de l'Institut International d'Etudes Ligures. $3^{e}$ éd.. 1975, p. 83-85, et tableau récapitulatif. p. 109-110.

(37) F. Benoit. loc. cit., p. 415 . H. : $6.5 \mathrm{~cm}: 1 .: 8 \mathrm{~cm}$ : è. : $2.5 \mathrm{~cm}$ : h. des lettres : $3 \mathrm{~cm}$ : Texte : ...CLA [... $800 \mathrm{~m} ?$

(38) Quelle raison aurait pu les pousser à aller la récupèrer, par exemple. dans la grande nécropole chrétienne de N.-D. de la Seds, distante de

(39) Voir sur ce point J. Guyon, A propos d'une inscription du cloitre Saint-Sanveur - la double vie posthume d'un clerc aixois : chanoine du $x \mu^{\prime \prime}$ siècle ou éveque du $V^{\prime \prime}$ siècle? dans R.A.N., 10. 1977, p. 199-216. 


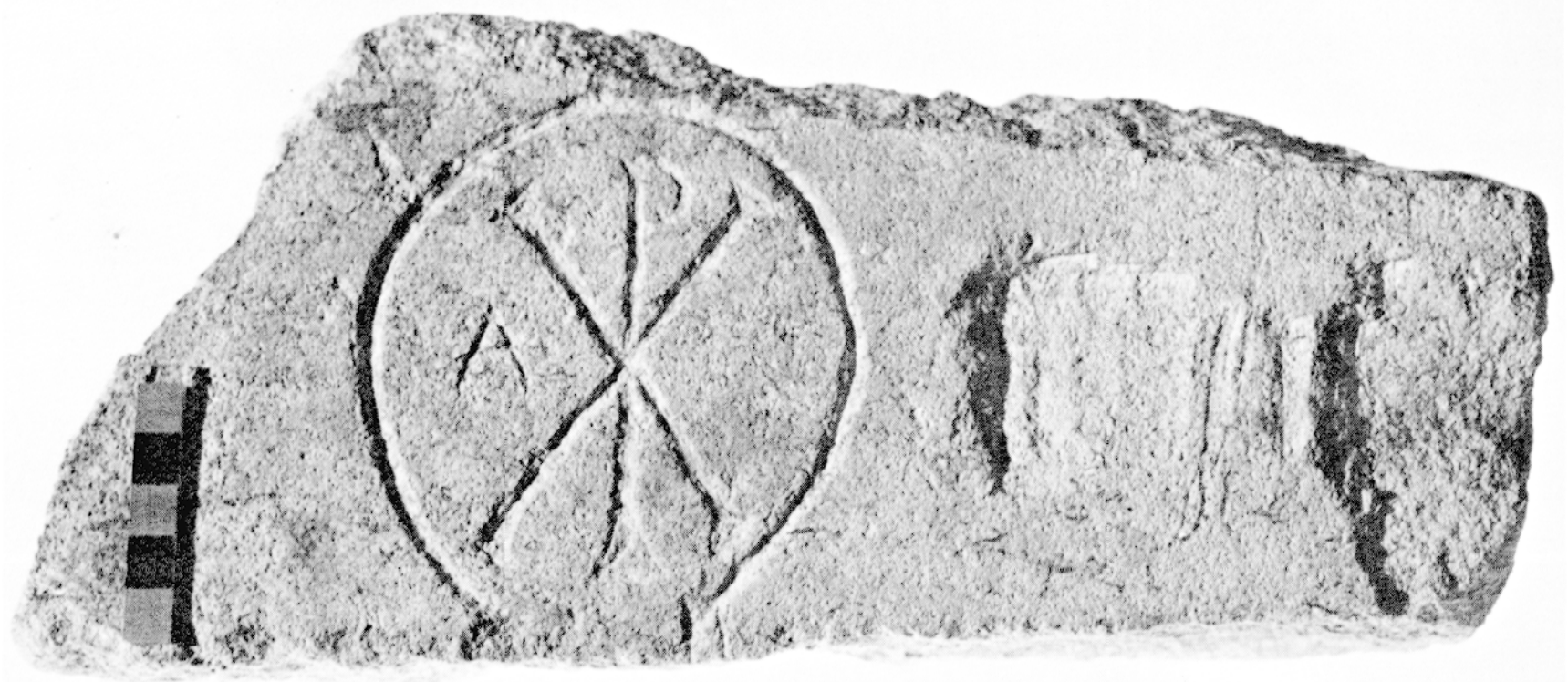

Fig. 14. - Fragment de décor avec chrisme provenant de la couche 4 du sondage 2 N. (Cliché C.N.R.S. - Chéné-Foliot).

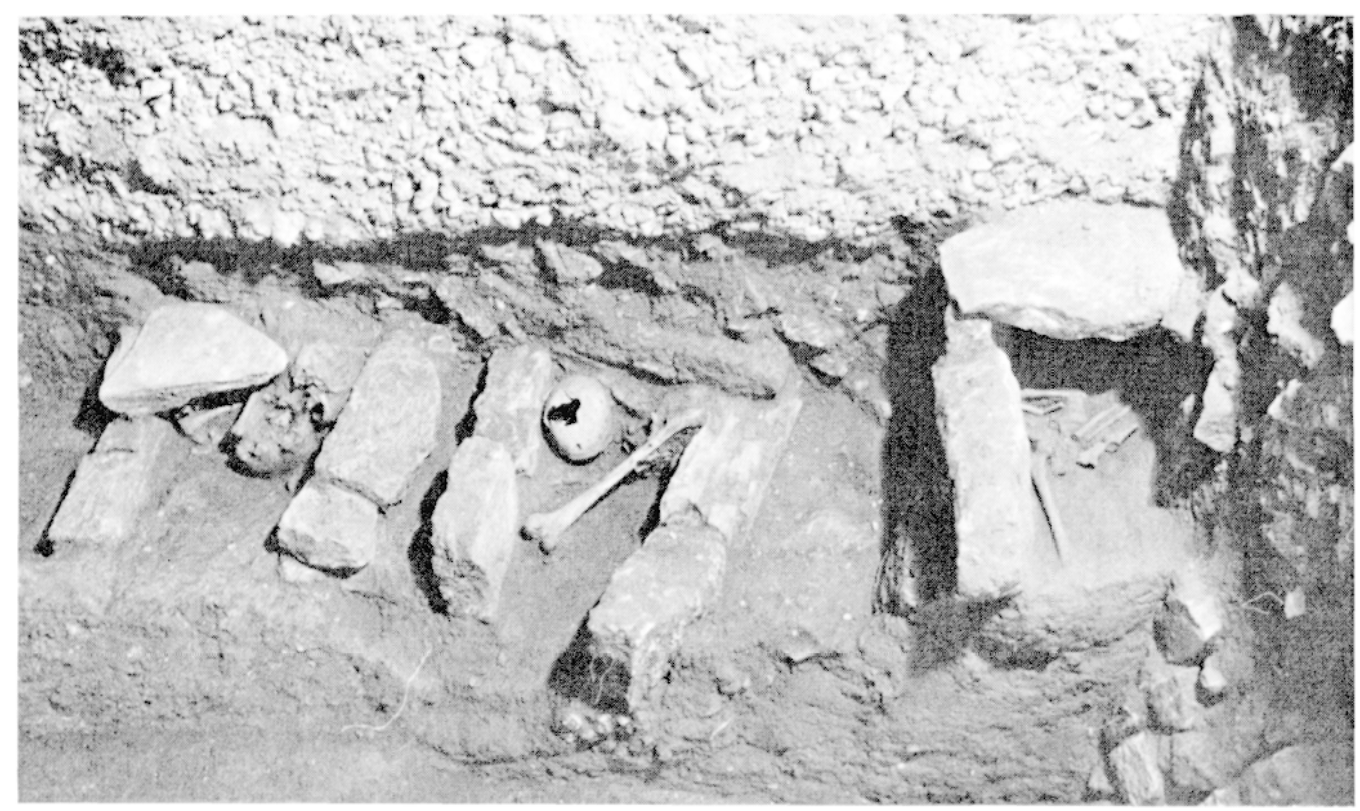

Fig. 15. - Sondage 5.

De g. à d. les tombes 1 à 3 vues de l'E. Au premier plan la grande tranchée d’époque médiévale tardive N./S. qui a détruit l'extrémité E. des coffrages: à l'arrière-plan les fondations du mur moderne de renfort de la paroi E. du cloitre appuyées sur les tombes. 
Trois inscriptions sans doute ne suffisent pas à faire à coup sûr une nécropole; du moins permettent-elles de supposer son existence, et il est donc possible (mais non certain) que le cimetière dont on a reconnu l'existence à Saint-Sauveur à date tardive ait été créé dès le $\mathrm{VI}^{e}$ siècle. Si cette hypothèse pouvait être vérifiée, elle fournirait, notons-le, un nouvel indice permettant de rattacher à la Basse-Antiquité la création du baptistère voisin.

\section{MOYEN-ÂGE ET TEMPS MODERNES}

\section{LA SITUATION AU XII SIĖCLE ET LA CREATION DU CLOÎTRE}

$\mathrm{Au} \mathrm{XII}{ }^{\mathrm{e}}$ siècle le niveau du sol est sans doute légèrement au-dessus de la cote $204,41 \mathrm{~m}$ (celle du remblai du Haut Moyen-Age probablement exhaussé alors par d'ultimes apports (40)) et les constructions ne manquent pas à cette date sur le site.

On en connait par des textes. La notice de consécration de l'église Saint-Sauveur (la nef romane de l'actuelle cathédrale) atteste l'existence au N. de ce bâtiment d'une église Notre-Dame, au S. de celle de Saint Jean-Baptiste (le baptistère), à l'E. d'un oratoire du Sauveur (la "Sainte-Chapelle » détruite en 1808) (41). Le document, daté de 1103, est sans doute plus tardif (42); il est sûr pourtant qu'il décrit bien le contexte monumental de la création du cloitre à la fin du XII siècle.

A côté de cet ensemble complexe d'édifices religieux, l'archéologie permet de supposer ou reconnaitre l'existence d'autres bâtiments dont la fonction nous échappe : dépendances du groupe épiscopal ? ou monuments civils?

C'est à l'O. que la situation est la moins nette. Le mur actuel de la galerie, qui s'aligne exactement au S. sur le mur E. du baptistère Saint-Jean est, on l'a dit, un mur ancien dont le parement et les fondations sont entièrement masques par un mur moderne de renfort, et il est impossible de savoir dès lors s'il est antérieur ou postérieur à la création du cloitre.

$\mathrm{Au} \mathrm{N}$. un seul point est sûr : le mur XVII est alors encore conservé, ou au moins visible à l'état de ruine, puisque les fondations de la niche à fond plat du mur E. du baptistère (infra, p. 138-140) s'appuient sur lui. Mais comme nous ignorons tout de l'extension du mur en direction de l'E. il est impossible d'avoir mème une idée des bâtiments existant dans cette zone.

A. l'E. le parement et les fondations du mur E. de la galerie présentent de multiples remaniements. Si l'on passe sur les détails on pourra distinguer deux secteurs principaux, de part et d'autre d'un chainage en grand appareil lisible sur toute la hauteur de l'élévation au droit du mur antique $\mathrm{V}$ (fig. 16).

Au N. le mur est directement fondé - à la cote $204,81 \mathrm{~m}$ - sur le mur antique I dont on a seulement entaillé les assises supérieures pour faire adhérer les blocs du parement qui font saillie par rapport aux fondations. L'élévation actuelle est certainement postérieure à la création du cloitre (elle remploie un fragment de chapiteau en pierre tendre de date tardive); mais il peut s'agir d'une réfection, car le mur est percé d'une porte sans doute ancienne.

C'est une ouverture cintrée large de $0,85 \mathrm{~m}$ et haute de $2 \mathrm{~m}$ dont le montant $\mathrm{N}$. est constitué d'un seul bloc - sans doute un remploi: le niveau du seuil - $204,91 \mathrm{~m}$ - suppose, s'il était surélevé d'un degré. que le sol alentour était à une cote plus proche de celle du cloitre que du niveau du Haut Moyen-Age. On jugerait donc la porte au moins contemporaine du cloitre si sa facture ne la rapprochait de monuments beaucoup plus anciens (43) : elle pourrait appartenir à l'äge pré-roman, et son niveau s'expliquerait par l'exhaussement progressif du sol du Haut Moyen-Age qui a laissé, on l'a dit, d'autres traces sur le site. Si cette analyse est juste. la partie septentrionale du mur serait bien antérieure au cloitre.

(40) On a quelques traces de remaniements tardifs du niveau du Haut Moyen-Age : cf par exemple supra, p. 131, n. 32.

(41) On trouvera ce texte notamment dans J.-H. Albanès. Gallia christiana novissima. I. Aix, Apı. Fréjus. Gap. Riez et Sisteron. Montbeliard. 1899. Instrumenta, col. 9 : "(...) consecrare ecclesiam Domini Salvatori noviter fundatam inter duas ecclesias videlicet versus septentrionem aecclesiann Dei Geneticis sitam, versus meridiem vero aecclesiam beati Johammis Babtiste positam, oratorio quoque eiusdem Domini nosıri Salvatoris versus orientem constructo" ".

(42) Cf. P.-A. Fèvrier, loc. cit., p. 57

(43) Les proportions de la porte. l'importance des claveaux, l'emploi d'un grand bloc monolithe pour piedroit sont autant de traits archaiques dont on trouverait d'autres exemples dans les édifices pré-romans de Provence comme la Trinité de Lérins. la chapelle de La Gayolle ou encore la tour du prieuré de Ganagobie. Pour ce dernier édifice. voir M. Fixot - J.-P. Pelletier. Fouille de sauvetage au prieuré de Ganagobie (Alpes de HauteProvence), dans Archéologie Médiévale, 6, 1976, p. 302. 


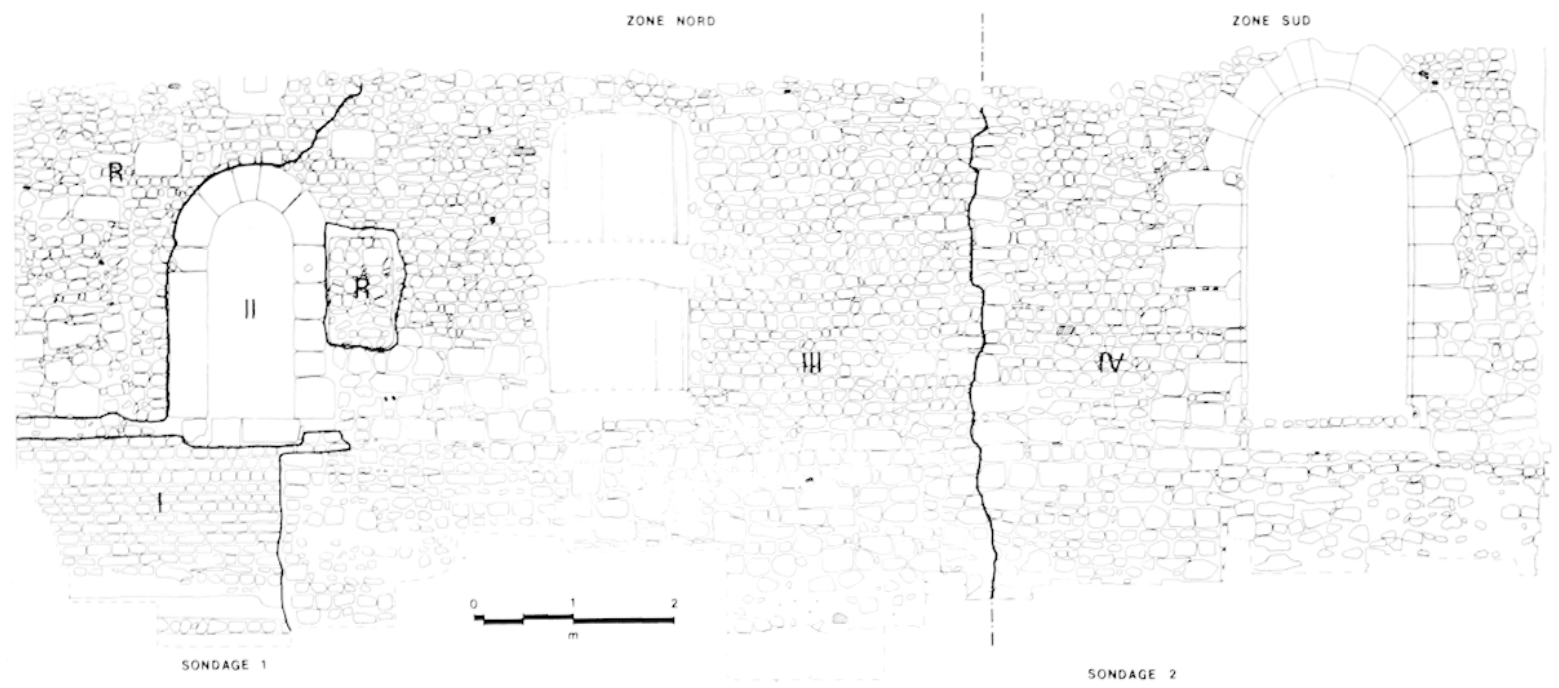

Fig. 16. - Elévation du mur E. du cloitre.

I : mur antique I; II : porte d'époque pré-romane (?); III : portion de mur antérieure à la création du cloitre (?); IV : mur d'époque indéterminée; $\mathbf{R}$ : remaniements.

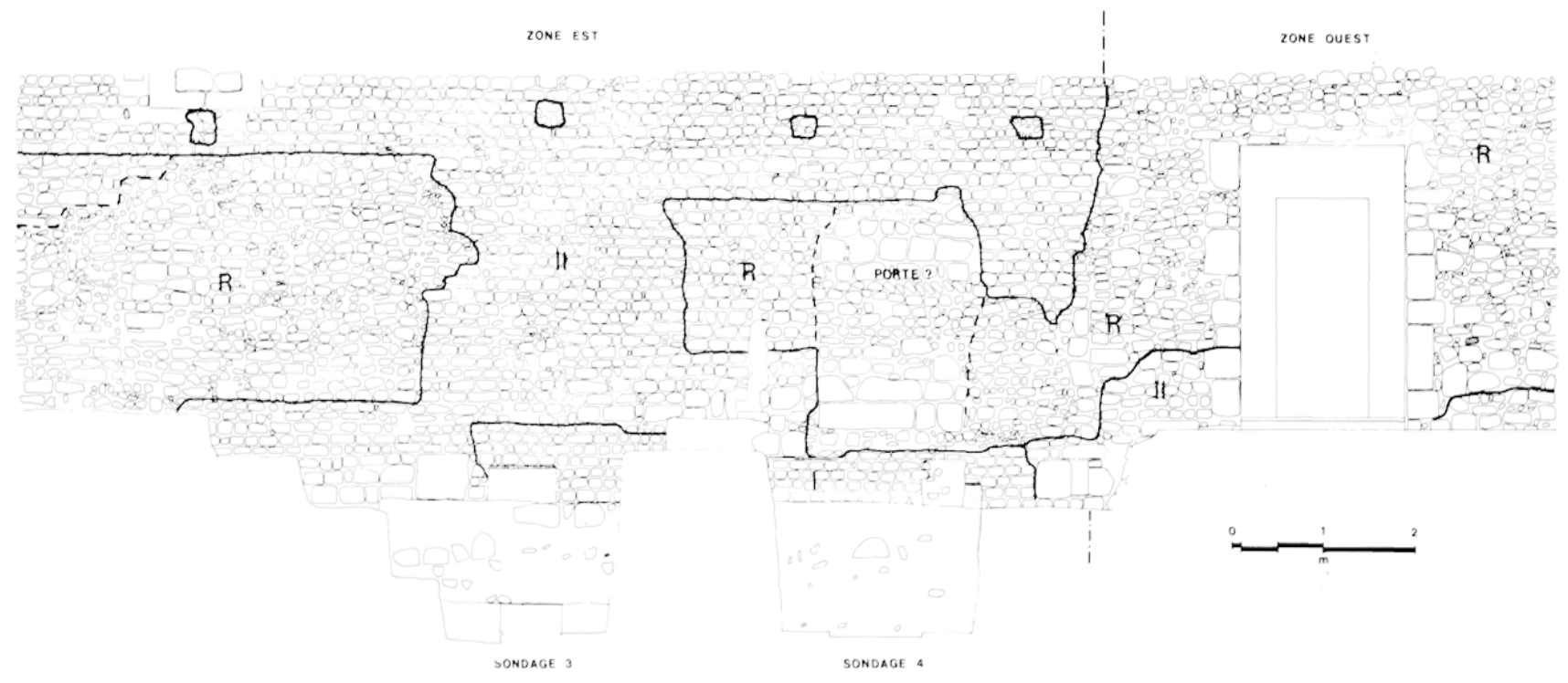

Fig. 17. - Elevation du mur S. du cloitre.

I : mur antique?; II : portions de murs antérieures à la création du cloitre; $R$ : remaniements.

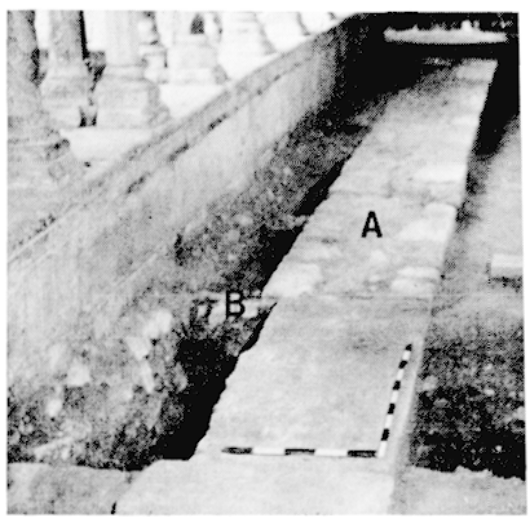

Fig. 18. - Galerie O. Le stylobate primitif du cloitre vu du N. A : stylobate primitif arasé au moment de sa destruction au niveau de la calade (B) couvrant la cour intérieure originelle du cloitre. Dans l'angle N.-O. la calade a été déposée pour les besoins d'un sondage au niveau des fondations des deux stylobates. 
Au S. du chaînage, où le trait marquant est la présence d'une porte monumentale tardive (infra, p. 140), on est seulement assuré que le mur $\mathrm{E}$. est postérieur au mur de la galerie $\mathrm{S}$. contre lequel il est appuyé; comme ce dernier mur, on le verra, est luimème antérieur au cloitre, la datation de la partie méridionale du mur E. reste dans le vague : elle peut être aussi bien antérieure que postérieure à la création du cloitre.

On notera que, pour la genèse du cloitre, la différence est mince entre ces deux hypothèses : il faut dans les deux cas supposer que le mur I était encore en fonction (en élévation ou en fondation sous une maison médiévale) au moment de sa création, le plan trapézoïdal de la galerie $E$. témoignant d'ailleurs suffisamment de la survivance à l'E. du cloitre d'un alignement préexistant.

L'élévation du mur S. n'est pas moins complexe, mais on peut pour l'instant n'étudier que la partie inférieure en y distinguant deux zones, de part et d'autre d'un coup de sabre situé $2 \mathrm{~m}$ à l'E. de l'actuelle porte d'entrée du cloitre, soit au droit du mur 0 . de l'édifice qui s'ètend au S. du cloître (la " maison du prévôt ") (fig. 17).

A l'E. du coup de sabre la base de l'élévation présente de telles similitudes avec les constructions tardo-antiques du site qu'il est possible, comme on l'a prudemment suggéré, supra, p. 127, qu'il s'agisse d'un mur antique réutilisé au Moyen-Age dans des conditions assez analogues à celles du mur I dans la galerie E.; à tout le moins, l'appartenance du mur à une époque assez haute du Moyen-Age est assurée par la présence du mur perpendiculaire XII qui est appuyé contre lui sur son ressaut de fondation (fig. 11) : on est sủr en effet que ce mur, visible sur une longueur de $0,40 \mathrm{~m}$ seulement, se poursuivait primitivement en direction du N. (44) (soit sur l'emplacement de l'actuelle galerie S. du cloitre).

Seules les fondations en blocage du mur XII, profondes de $0.45 \mathrm{~m}$, sont conservées, et le niveau du sol qui lui était associé est sans doute le même que celui du sol recouvert de mortier qui s'appuie contre le mur $\mathrm{S}$. à la cote $204.41 \mathrm{~m}$; c'est en tout cas audessous de ce niveau qu'on trouve, $1 \mathrm{~m}$ environ à l'O. du mur XII, une cavité large de $0,18 \mathrm{~m}$ et profonde de $0.25 \mathrm{~m}$, qui passe audessous du mur $\mathrm{S}$. en un point où ses parois et sa couverture sont faites de blocs en grand et moyen appareil : c'est une canalisation de drainagc qui a été remplacèe après la construction du cloitre par un égout plus important.

Le niveau d'occupation et la direction du mur XII montrent suffisamment que ce mur et la partie orientale du mur $\mathbf{S}$. appartiennent à des bâtiments antérieurs à la création du cloitre.

Il est difficile de dire s'il en est de mème pour la partie à l'O. du coup de sabre : on n'a pu ici reconnaitre les fondations, et l'ouverture de la porte gothique tardive d'accès au cloitre a entrainé des remaniements trop importants pour qu'on puisse restituer à coup sûr l'état originel du parement; il n'est pas exclu toutefois qu'il s'agisse aussi d'un mur ancien, percé dès l'origine d'une porte à l'emplacement de la porte gothique (45).

Il est sûr qu'il existait sur le site avant même la création du cloitre une série de constructions, d'ampleur et de fonction exactes inconnues, dont le plan dessinait dans ses grandes lignes le quadrilatère à l'intérieur duquel s'inscrit la nouvelle construction, plus vaste que le monument actuel.

A 1,50 m environ à l'O. du stylobate de la galerie 0 . du cloitre et sensiblement parallèle à lui, on a en effet retrouvé les fondations d'un stylobate primitif qui donne au premier cloitre d'Aix une ampleur qu'on ne lui soupçonnait pas.

Sauf dans les angles où ont èté remployés des blocs en grand appareil, les fondations, larges de $0,75 \mathrm{~m}$ et profondes de $0,40 \mathrm{~m}$, sont constituées d'un blocage encadré par deux parements de moellons (fig. 18). Autant qu'on ait pu le vérifier, dans la seule galerie E., c'est d'une façon analogue qu'a èté fondé le stylobate $E$., à cette différence près que, si l'angle N.-E. repose bien sur des blocs en grand appareil, l'angle S.-E. est au-dessus d'une couche d'effondrement de moellons et de blocs. L'élévation du stylobate compte de nombreux remplois, seuils, montants de porte, et mème, on l'a dit, une inscription sur marbre.

L'espace à l'E. du stylobate (la cour intérieure primitive du cloitre) est couvert d'une calade faite de galets de rivière. C'est un sol récent, certainement dú à une réfection, car son démontage a livré de la céramique vernissée d'èpoque moderne (mais pas de céramique contemporaine).

La restitution du cloitre primitif semble s'imposer : il faut supposer que les galeries $\mathbf{N}$. et $\mathbf{S}$. comptaient à l'origine une arcade de plus qu'aujourd'hui, donnant au monument la forme d'un rectangle mesurant environ $12 \mathrm{~m}$ d'E. en $\mathrm{O}$. pour $10,75 \mathrm{~m}$ du N. au S. (fig. 19).

En toute rigueur pourtant, elle n'est pas totalement assurée : on pourrait en effet imaginer que lorsqu'on a modifié la galerie O. (infra, p. 140) on a aussi déplacé l'ensemble du monument vers l'E. Dans ce cas, on devrait trouver à l'O. du stylobate E. les restes d'un stylobate primitif analogue à celui qui a été fouillè dans la galerie $O$. L'impossibilité d'ouvrir un sondage dans la cour nous a interdit de vérifier cette hypothèse, à vrai dire peu vraisemblable si l'on s'avise d'une part qu'avec la restitution que nous

(44) On a trouvé en effet dans l'alignement du mur et à la cote de la base de ses fondations des traces sporadiques de mortier qui traversent le sondage 4 en direction du N.: en outre une poche. trés lisible en stratigraphie. pourrait témoigner de la récupération ancienne des matériaux.

(45) A l'E. de cette porte on trouve en effet deux blocs en grand appareil (cf. fig. 17) qui pourraient appartenir au montant E. d'une porte plus ancienne qu on jugerait volontiers anterieure au cloitre : elle ouvre en effet. non pas dans l'axe de la galerie $O$.. mais tres a l'E. de celui-ci. et cette disposition étrange s'expliquerait bien si l’on a réutilisé une installation préexistante. 


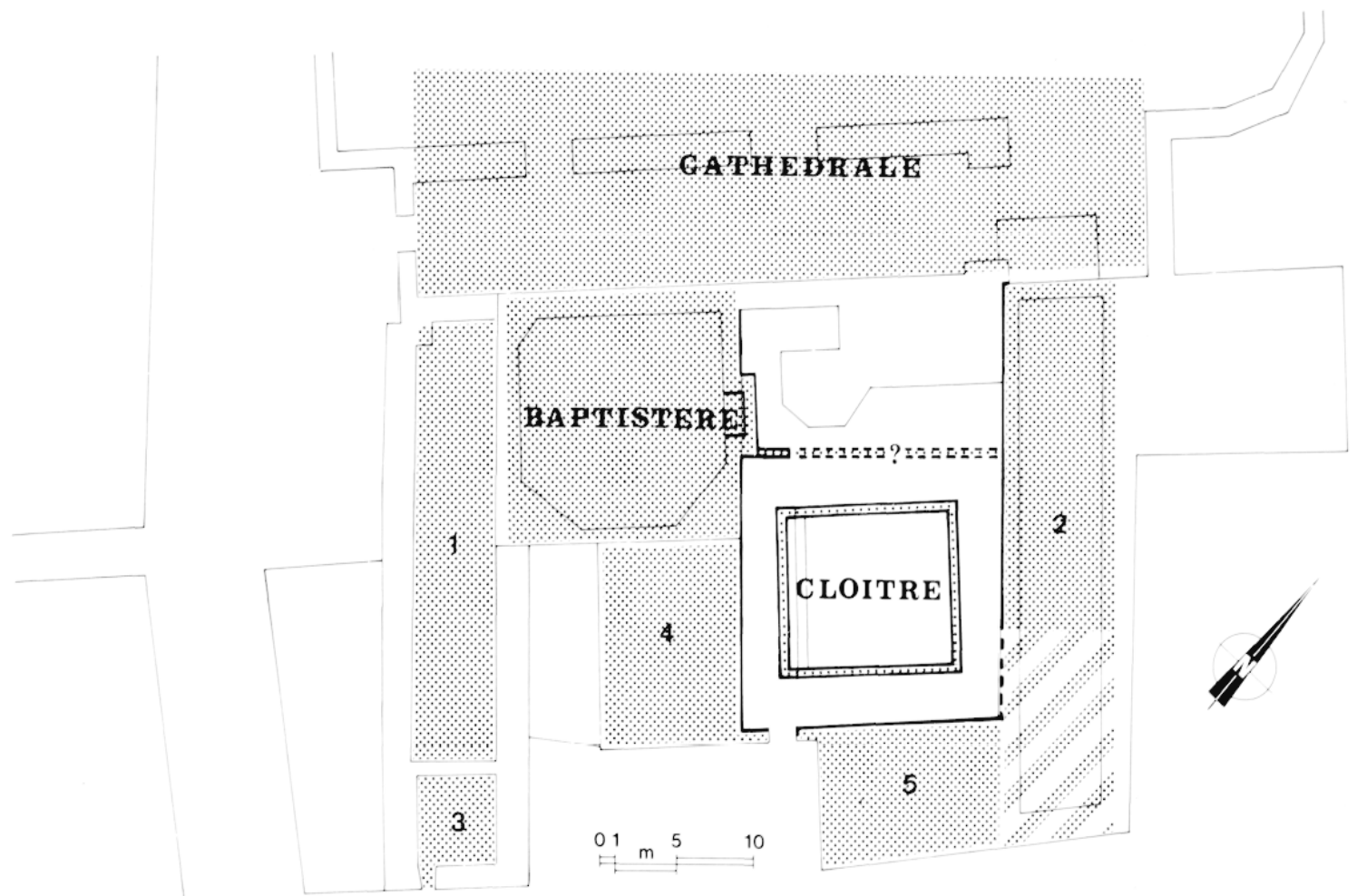

Fig. 19. - Schéma de situation au XIVe siècle. (On a choisi cette période pour laquelle on dispose de renseignements sûrs, mais beaucoup d'édifices alors présents sur le site remontent à la fin du XII siècle).

1 à 5 : bâtiments canoniaux ( 5 : « maison du prévôt $»)$.

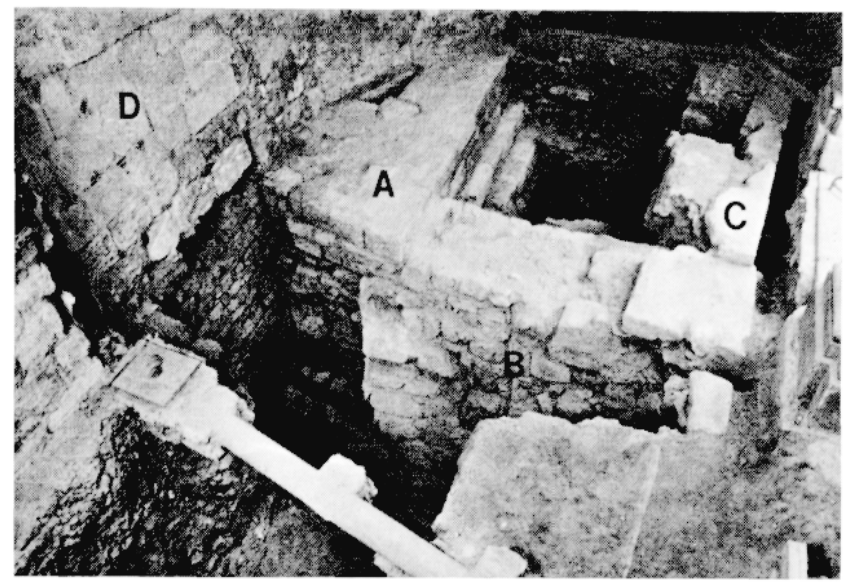

Fig. 20. - Sondage 8 .

Vue générale du S.-E.

A : niche à fond plat de la paroi $E$. du baptistère; $B$ : mur XVIII ; C : mur XIX; D : rebouchage de l'enfeu (?) aménagé sur la paroi E. du baptistère (cliché C.N.R.S. - Chéné-Foliot).

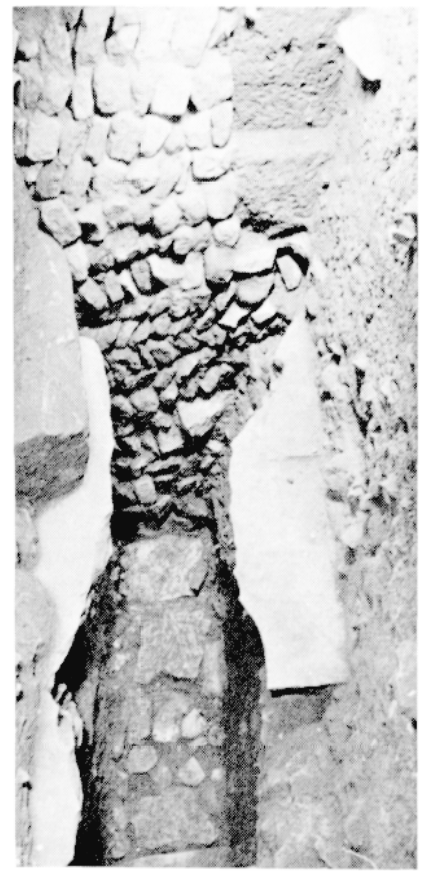

Fig. 21. - Sondage 5 vu du S.

Tranchée N./S. ayant entaillè le dallage romain pour l'installation dun caniveau dont on voit au fond les dalles de couverture: à l'arrière plan, le mur XIV servant à retenir la terre de comblement de la tranchée. 
avons proposée les galeries mesurent régulièrement $2.75 \mathrm{~m}$ de large en moyenne (46), et d'autre part que l'ouverture dans le stylobate qui permet au $\mathrm{N}$. d'entrer dans la cour est exactement au centre du stylobate $\mathrm{N}$. restitué.

Il est plus malaisé en revanche d'imaginer l'environnement du cloître : les galeries ont-elles été entièrement fermées dès l'origine, ou subsistait-il alors de larges espaces ouverts à côté des bâtiments dont nous avons cru retrouver les traces, et dont la seule présence suffisait à dessiner largement le quadrilatère à l'intérieur duquel s'inscrit le cloitre?

Une réponse trop catégorique est impossible, mais il est vraisemblable que le cloitre a été assez vite complètement clos, ce qui a permis aussi de lui donner une couverture.

On notera en tout cas dans le parement du mur S., $3 \mathrm{~m}$ environ à l'O. de la porte gothique, des blocs en grand appareil qui ont pu appartenir au seuil d'une porte maintenant rebouchée dont le gabarit restituable $(1,90 \mathrm{~m} \times 0,90)$ et la cote $(205 \mathrm{~m}$ env.) sont très voisins de ceux de la porte $\mathrm{N}$. de la galerie $\mathrm{E}$. (fig. 17). Si l'on ajoute qu'on trouve près de l'extrémité $\mathrm{E}$. de ce mème mur l'embrasure d'une fenêtre originelle (?) peut-être transformée en porte (si l'on en juge du moins par la cote des trous de poutres voisins portant la couverture primitive de la galerie) (47), il est clair que le bâtiment jouxtant le cloitre au S. a bien été transformé pour pouvoir communiquer avec lui (48).

Sans pouvoir dater ces transformations on serait tenté de les placer à une date assez haute en considérant que la maison qu'elles touchent sert de limite S. au groupe épiscopal ; on imaginerait volontiers qu'elles appartiennent au programme d'envergure qui a édifié autour de la cathédrale, du cloitre et du baptistère des annexes aussi importantes que le "bâtiment à bossages" construit au-dessus du mur de la Basse-Antiquite empiétant sur le cardo (supra, p. 128). Si l'on retient cette hypothèse, on pourra attribuer au mème programme l'achèvement du mur de la galerie 0 . qui limite à l'E. les dépendances $O$. du groupe épiscopal (49) (fig. 19).

Il n'est finalement que la limite $\mathrm{N}$. qui reste imprécise. Jusqu’à une date récente la galerie $\mathrm{N}$. était ouverte, mais cette situation n'est peut-être pas originelle. Bien que nous ignorions tout des limites E. du mur XVII, la vraisemblance commande en effet de restituer en élévation à son emplacement un mur fermant le cloitre au N., qui délimiterait une galerie de largeur comparable à celle de ses voisines; si l'on en juge par le relevé, malheureusement assez imprécis, qui figure sur le plan d'Aix d'E. Devoux (1753) (50), ce mur supposé aurait peut-être d'ailleurs été encore effectivement en service, au moins partiellement, dans la seconde moitie du XVIII ${ }^{\mathrm{e}}$ siècle.

\section{2. - LA NICHE À FOND PLAT DU MUR E. DU BAPTISTÈRE ET SA RÉPARATION DANS LA SECONDE MOITIÉ DU XIV' SIËCLE}

Rien ne permettait avant la fouille de soupçonner l'existence d'un état primitif du cloître, et sa découverte a été pour nous une surprise; on avait quelque raison de penser en revanche que le baptistère n'avait pas toujours eu à l'extérieur le volume cubique qu'on lui connaît, qui passe pourtant pour l'un des garants de sa possible antiquité (51). Et de fait, la fouille a montré qu'au Moyen-Age au moins la niche médiane de la face orientale du baptistère saillait de $0,60 \mathrm{~m}$ environ hors du droit du mur $\mathrm{E}$.

(46) La remarque vaudrait même pour la galerie $N$. si l'on suppose qu'il a existé un mur fermant le cloître dans cette direction, fondé sur le mur XVII conservé (infra. mème page). Seule la galerie E.. de largeur inégale. fait exception: mais elle doit. comme on l’a vu, son plan trapézoidal à la réutilisation à l'E. d'un alignement préexistant au cloitre.

(47) Cette couverture était établie environ $0.40 \mathrm{~m}$ au-dessous de la couverture actuelle, restituée au début du siècle par les soins des Monuments historiques (infra, p. 144).

(48) On notera que la communication pouvait peut-être aussi se faire directement avec le premier ètage si l'on doit interpréter comme les restes d'un escalier les traces de reprise dans le parement du mur à proximité de la porte-fenêtre (fig. 17).

(49) Ce mur pourrait ètre assez ancien : il limite à l'E. un bảtiment qui semble avoir été réuni à la "maison médiévale " qu'on a reconnue au S.-E. du cloitre par le mur dans lequel est percée la porte gothique tardive d'accès au cloitre: or cette porte aurait remplacé une ouverture primitive elle-mème antérieure (supra. p. 136).

(50) On le trouvera reproduit notamment dans l'ètude d' $\Lambda$. Poher. Le palais des archev'éques d'Aix du xh' au xvil' siècle, mémoire de maitrise dactylographie. Aix. 1974, pl. 66-67.

(51) A tort d'ailleurs : il y avait par exemple à l'O. du baptistère de Marseille une annexe importante - dailleurs incomplètement fouillée qui rompait l'ordonnance du volume cubique extérieur : cf. X. Barral i Altet - D. Drocourt, loc. cil., fig. 7. p. 13. A Aix ou dautres indices de l'antiquité du baptistère ne manquent pas (supra, p. 129) l'annexe E. (au N. du mur XVII) pourrait avoir joué un rôle analogue. et le plan de la niche médiévale ne serait alors qu'une survivance de l'Antiquité. Cette interprétation se fonde sur l'articulation des édifices retrouvés par la fouille: elle reste pourtant hypothétique. Il est sûr en revanche qu'il a existé dès le premier ètat du baptistère médiéval une niche (d'ampleur exacte inconnue) à l'emplacement de celle retrouvée par la fouille. l'étude de l’èlévation du monument suffisant à assurer son existence. Sur ce point. voir S. Rollins Guild. Une quatrieme géneration d'hypotheses sur les problemes de chronologie. de sens et de signification originelle des parties romanes de la catheidrale Sainl-Sauveur d'Aix-en-Provence, mémoire de maitrise dactylographiè de I'Universite de Provence (Aix-Marseille I). Aix. 1976. p. 184. 
On n'a retrouvé que les fondations de cette niche, soigneusement arasées à la cote $204.71 \mathrm{~m}$. Son mur S. épais de $1.20 \mathrm{~m}$ s'appuie sur le mur XVII préexistant tandis que le mur E., large de $0.80 \mathrm{~m}$ seulement, a tranché le sol et le caniveau de la BasseAntiquité décrits supra, p. 127 pour s’appuyer sur les dalles du Haut-Empire. L'appareil, fait de moellons et surtout de blocs de pierre de taille. est particulièrement soigné: fondé en tranchée jusqu'au niveau tardo-antique. il est construit en élévation au-dessus (fig. 20). Deux ressauts de fondation, larges de $0.20 \mathrm{~m}$ chacun, sont présents dans le mur E.: sans doute la base du second marquet-elle le début de l’élévation.

Une minimc portion de l'angle internc de la niche a pu être dégagée : c'est assez pour connaitre la cote du pavement $(204,58 \mathrm{~m})$ et vérifier que le sol et les murs ont èté revêtus d'un placage de marbre blanc veinè de vert.

On connait les dimensions de cette niche, dont on suit l'élévation en blocs de moyen appareil, non pas dans le cloitre où elle a été détruite, mais dans le tambour d'accès à la cathédrale où l'on retrouve le coup de sabre qui marque sa limite $\mathrm{N}$. : longue de $5 \mathrm{~m}$ environ à l'extérieur, elle est large de $2.60 \mathrm{~m}$ à l'intérieur pour une profondeur de $1.25 \mathrm{~m}$.

Un examen de l'élévation intérieure du baptistère, actuellement privée de son enduit, montre que la niche retrouvée par la fouille n'appartient pas au premier état du bâtiment : elle s'inscrit en effet à l'intérieur d'une arcature plus ample de l'élévation primitive. En l'absence d'une fouille de l'intérieur du baptistère (dont l'intérêt serait grand, et pas seulement pour l'époque médiévale) il est impossible d'apprécier exactement la signification des restes retrouvés : sont-ils une simple réfection de la niche primitive ? ou répondentils à une extension vers l'E. d'une niche originelle de même ampleur que celles aujourd'hui conservées ? On pourrait également se demander si toutes les niches latérales ont connu une semblable extension, ou si l'on a seulement voulu mettre l'accent sur la niche orientée, spectaculairement surhaussée (elle domine de 0,50 m le sol actuel du baptistère (52). Autant de questions pour l'instant sans réponses.

On éprouvera le même embarras pour dater la construction de la niche; les données de la fouille permettent seulement d'affirmer qu'elle est antérieure à d'importants travaux de restauration dont par chance la chronologie est cette fois assez précise.

De profondes lézardes ont en effet affecté non seulement les fondations de la niche au niveau où elles s'appuient sur le mur XVII, mais aussi ce mur lui-même (cf. fig. 9). Ces dégâts sont dûs à des infiltrations, qui ont pu se produire aussi bien au $\mathrm{S}$. du mur (où le caniveau dans l'angle des murs XVII et XX est peut-être resté longtemps en fonction) qu'au N. oủ l'on a retrouvé le sol du Bas-Empire et le remblai sous-jacent profondément affouillés par les eaux.

La réparation de ce sinistre a nécessité une intervention denvergure. On a creusé en toute hâte au S. du mur XVII endommagé un " trou d'homme " de forme irrégulière, jusqu’à atteindre le niveau des infiltrations, et l'on a mis ensuite en place un drain pour assécher la zone.

C'est à la cote $201,56 \mathrm{~m}$ qu'il a fallu travailler, en ouvrant une tranchée de direction N.-E./S.-O. large de $0,60 \mathrm{~m}$ à $0,80 \mathrm{~m}$ que la fouille a retrouvée sur une quinzaine de $\mathrm{m}$ de longueur dans les sondages 5 à 8 . Le travail, assurèment malaisé (il a fallu casser les dalles romaines pour maintenir la pente nécessaire à l'écoulement) a été exécuté tres rapidement en progressant vers le $S$. par sections de $2 \mathrm{~m}$ de long environ : sitót une portion ouverte, on a installé le drain. un caniveau large de $0.15 \mathrm{~m}$ et profond de $0,20 \mathrm{~m}$, aux parois et à la couverture en pierres, au fond en terre; après avoir ouvert la section suivante, on a rebouché la première avec la terre qu'on en avait extraite en l'adossant à un mur de moellons liés à l'argile dont le profil incliné sert à contrebuter la masse du remblai qu'il retient, et ainsi de suite. Trois de ces murets, les murs XIII, XIV et XV. ont été retrouvés dans chacun des sondages, et deux d'entre eux au moins, XIV et XV, sont particulièrement soignés (fig. 21 ).

La zone enfin asséchée, on a renforcé l'angle S.-E. de la niche en construisant en élévation dans une tranchée large de $0,60 \mathrm{~m}$ un mur puissant, le mur XVIII, compose de moellons de grande taille et de blocs en grand appareil (dont de nombreux remplois, dalle, bossage, imposte) liès par un mortier tenace. On a reconnu ce mur sur une longueur de $2 \mathrm{~m}$ seulement, mais il est sûr qu'il se poursuivait en direction de l'E. hors des limites du sondage.

Ce travail a pris assez de temps pour que les terres remblayant la tranchée de construction aient recueilli, mèlés à la céramique antique, des tessons de céramique vernissée moderne, qui sont rares au contraire dans le remblai de comblement de la tranchèe du drain plus hâtivement rebouchée (couche $2 \mathrm{~b}$, sondages 5 à 8 , fig. 30). Le matériel est suffisamment abondant pour permettre de dater les réparations du milieu ou, plus súrement, de la seconde moitiè du XIV ${ }^{e}$ siècle (53).

On tient donc un terminus post quem non pour l'édification de la niche, dont on peut se demander s'il est très éloigné de la date réelle de sa construction quand on remarque l'abondance des matériaux de remploi de bonne qualité dans le parement de fortune du mur XVIII. L'hypothèse la plus simple est sans doute qu'ils proviennent de l'écroulement au moins partiel de l'élévation du monument, mais il est également possible qu'il s'agisse de matériaux prêts à l'emploi qu'on aurait réutilisés hâtivement pour réparer des dégâts

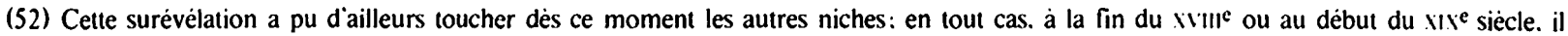
existe un degré pour accéder à chacune des niches, comme le montre un plan conservé à la Bibliothèque Mèjanes d'Aix-en-Provence (Est. A 33).

(53) Voir dans l'annexe consacrée à la céramique. infra. p. 153. la note sur ce matériel rédigée par L. Vallauri. 
survenus pendant la construction même de la niche. Les données de la fouille ne permettent pas de trancher entre ces deux interprétations.

On a également réaménagé dans cette zone l'accès à la cathédrale en construisant un mur, le mur XIX, dont il ne reste plus que les fondations, larges de $0,70 \mathrm{~m}$ et faites de blocs en remploi (?) de pierre de taille qui reposent à la cote $204,51 \mathrm{~m}$, au N. sur un remblai, au S. sur le mur XVIII. Sans doute l'élévation était-elle sensiblement à l'alignement du mur O. de la chapelle de SainteCatherine qui ferme à l'E. le tambour d'accès à l'église. Il est vraisemblable pourtant que le mur est postérieur, fût-ce de peu, à la chapelle, car il a été construit au-dessus d'un caniveau couvert (54), large d'une vingtaine de $\mathrm{cm}$ et profond d'autant, dont le cours incurvé épouse le tracé du mur extérieur de la chapelle.

Si l'on remarque pourtant que ce dernier bâtiment est sensiblement contemporain des ouvrages que nous avons décrits jusqu'ici - on le date généralement du XIve siècle (55) - , on pourra proposer, pour simplifier, de rattacher à une seule et mème campagne de travaux les constructions ou modifications importantes de la zone au N.-O. du cloitre, qui ne semble pas lui-mème avoir été transformè.

On en terminera avec l'époque médiévale en mentionnant deux dernières transformations, la réfection de la porte d'entrée S.O. du cloitre à époque gothique tardive et la construction d'une maison au-dessus de l'angle N.-E. du cloitre. On s'attardera un instant sur ce dernier monument que la fouille a permis de mieux connaitre.

Pour laisser libre la circulation sous l'emprise de la maison on a choisi de faire reposer l'élévation sur un arc brisé de grande portée (7,00 m environ) dont le pilier $\mathbf{N}$. est adossé à l'un des contreforts de la cathédrale, tandis que le pilier $\mathrm{S}$. masquait jusqu'à une date récente le décor roman du pilastre N.-E. du cloitre. Le report vers le $\mathrm{N}$. de ce pilier interdit d'étudier l'élévation originelle (56); du moins a-t-on retrouvé ses fondations dans le sondage 1. C'est le mur IX, constitué de blocs en grand appareil sommairement jointoyés à l'argile et au mortier blanc, qui ont été déposés dans une tranchée profonde de plus de $2 \mathrm{~m}$ dont la base est au niveau de l'argile vierge.

A défaut d'un quelconque matériel retrouvé dans la tranchée, c'est le style de l'arc brisé soutenant la maison qui permet de la rattacher à l'époque médiévale tardive.

\section{3. - LES TRANSFORMATIONS DU CLOÎTRE À L'ÂGE CLASSIQUE}

C'est sans doute à date relativement tardive que le cloître prend progressivement son aspect définitif, au prix de modifications relativement mineures à l'E., beaucoup plus radicales à l'O.

A l'E., on remarque surtout dans la partie méridionale du mur de la galerie la construction d'une porte cintrée monumentale (elle mesure 1,60 m de large pour une hauteur de $2,70 \mathrm{~m}$ ) donnant accès à la grande salle voûtée qui jouxte le cloître à l'E. (cf. fig. 16). Elle est si parfaitement insérée dans le mur qu'elle perce qu'on peut se demander si celui-ci n'a pas été refait ou mème construit en mème temps qu'elle (57), surtout si l'on considère la présence en fondation d'un puissant contrefort dont l'existence ne peut guère s'expliquer que par la création de la porte; large au maximum de $0,40 \mathrm{~m}$ et long de plus de $3 \mathrm{~m}$, ce contrefort est, semble-t-il, fondé sur le niveau de la Basse-Antiquité 5 a qu'on a présenté supra p. 125 (58).

A l'O., la modification la plus spectaculaire a été l'agrandissement de la galerie 0 . dont la largeur a été portée à $4,50 \mathrm{~m}$ par la suppression de l'arcade $\mathbf{O}$. des colonnades $\mathrm{N}$. et $\mathrm{S}$. du cloitre. Le nouveau stylobate $\mathbf{O}$. n'est pas strictement parallèle au premier (de sorte que le plan du cloitre actuel n'est pas un rectangle parfait); autant qu'on ait pu le vérifier, ses fondations en moellons sont soignées et l'élévation remploie sans doute très largement les matériaux de la construction primitive.

On a également supprimé l'angle $\mathrm{S}$. $\mathrm{E}$. de la niche à fond plat du baptistère, peut-être parce qu'elle restait fragile malgré les réparations dont elle avait été l'objet, plus probablement sans doute parce que sa destruction permettait d'ouvrir plus amplement l'accès de la cathèdrale à l'extrémité de la galerie $\mathrm{O}$. élargie (surtout si, comme il est probable, le mur XIX a èté en même temps arasè). Au N. de l'arrachement du mur $\mathrm{S}$. de la niche l'angle du monument détruit a èté bouché par un parement en grand appareil que l'on retrouve au S. où il obture une large ouverture couverte par un arc segmentaire (fig. 22). Les dimensions que l'on doit restituer à cette ouverture presque à demi masquée par le mur moderne renforçant le mur du baptistère ( $3 \mathrm{~m}$ de large pour une hauteur de $2,30 \mathrm{~m}$ ) et surtout sa localisation à proximité de l'angle S.-E. du baptistère interdisent de l'interpréter comme une porte : il faut sans doute songer plutôt à une niche, ou un enfeu qu'on a jugé utile alors de supprimer.

(54) Il était sans doute destiné à évacuer les eaux de pluie collectées sur la couverture de la niche du baptistère.

(55) La première mention de la chapelle de Sainte-Catherine est de 1317 : cf. J. Pourrière, Aix-en-Provence, rues et momuments. Aix. 1952. p. 194.

(56) Cette transformation est à l'origine des trouvailles de 1958: c'est elle qui a nécessité l'importante coulée de béton qui a beaucoup gèné la recherche dans les sondages 1 et 9

(57) On a signale supra, p. 136. qu'il est impossible de dater précisément cette portion de mur joignant deux constructions médièvales (mur $\mathrm{S}$ et partie $\mathrm{N}$. du mur $\mathrm{E}$. du cloitre).

(58) Il est impossible d'indiquer en toute certitude la cote de ces fondations. la fouille nayant pas depassé dans cette zone le niveau de la BasseAntiquité. 


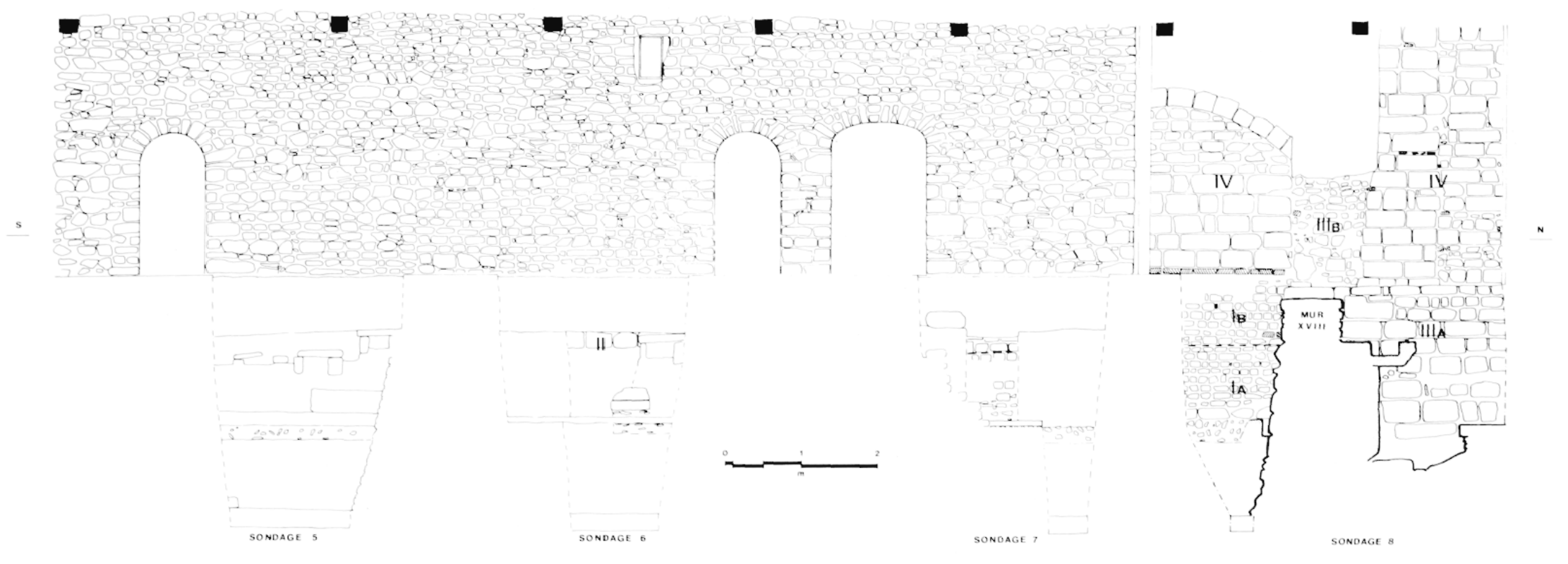

Fig. 22. - Elévation du mur O. du cloitre.

IA : mur XX, partie inférieure; IB : mur XX, partie superieure; II : fondations peu profondes de la partie de mur au S. du baptistère: IIIA : fondations de la niche à fond plat du baptistère: IIIB : arrachement du mur $S$. de la mème niche: IV : rebouchage de la niche (au N.) et de l'enfeu (?) de la paroi E. du baptistère (au S.). 
Enfin on a barré l'accès des galeries $\mathrm{N}$. et $\mathrm{S}$. par deux portes s'ouvrant entre des piliers adossés respectivement aux murs des galeries et aux pilastres d'angle du cloitre; au moment de la suppression de ce dispositif en 1958 on a cependant conservé la porte $\mathrm{N}$. qu'on a simplement déplacée au $\mathrm{N}$. de la galerie $\mathrm{N}$. du cloitre couverte pour l'occasion d'une charpente.

Ces différentes transformations ont eu pour effet d'isoler la plus grande partie du cloitre " pour la bienséance et empêcher que les personnes läques n'y entrent et fassent des indéssenses " comme le dit une délibération du Chapitre de 1667, décidant " qu'on fera clorre les chapiteaux (c'est ainsi qu'on appelle alors le cloitre) ainsi qu'ils estoyent auparavant "(59).

Seule la galerie 0 . est alors "un passage ». Ce terme que l'on trouve significativement employé à l'occasion (60) n'est nullement dépréciatif, car cette galerie d'accès à la cathédrale a bien été élargie et monumentalisée en même temps qu'était isolé l'espace réservé aux chanoines (qu'on a également transformé par l'ouverture de la grande porte de la galerie E.). La solution architecurale adoptée est élégante, qui a permis, sans détruire le cloître roman, de l'adapter à un nouvel usage - ou à une nouvelle sensibilité des chanoines.

Une chronologie précise de ces différentes transformations est impossible à fournir; du moins quelques indices permettent-ils de les placer auX XVII ${ }^{e}$-XVIII ${ }^{\mathrm{e}}$ siècles.

Pour dater l'élargissement de la galerie 0 . (et sans doute aussi la démolition de la niche du baptistère, cet autre élément important du réaménagement de l'accès à la cathédrale) on s'appuiera sur la documentation épigraphique.

L'examen des copies conservées de l'inscription remployée dans le stylobate de la galerie O. (supra, p. 132) montre en effet que les lectures du début du XvII siècle (B. Burle, N. Peiresc) sont moins complètes que celles du début du XIXe siècle (Fauris de Saint-Vincens), non à cause de la maladresse des épigraphistes, mais parce qu'on a déplacé entre temps la pierre. rendant lisibles du coup cinq à six caractères supplémentaires au début de chaque ligne : le déplacement ne fait aucun doute, car l'on voit encore maintenant sur le marbre les traces de la base de colonne géminée qui reposait primitivement sur sa partie g. Comment douter aujourd'hui que cette modification, qui avait déjà èté remarquée (61), n'est pas contemporaine de tout le réaménagement de la galerie $\mathbf{O}$. du cloitre?

Dans l'intervalle - XVIle-XVIII siècles - ouvert par l'épigraphie, on placerait volontiers à une date assez haute ces transformations si l'on s'avise que les lettres que le déplacement de la pierre a permis de découvrir aux premières lignes de l'inscription étaient déjà très usées quand Saint-Vincens les copia en 1819 (62).

La présence de céramique moderne (mais non contemporaine) dans la calade à l'E. du stylobate primitif (supra, p. 136) va bien dans le sens de cette datation qui pourrait convenir aussi à la porte de la galerie E. qu'on ne saurait imaginer trop tardive, car elle a vraisemblablement été rebouchée au plus tard au début du XIX' siècle (infra, p. 143).

La condamnation des galeries $\mathrm{N}$. et $\mathrm{S}$. pourrait être un peu plus récente : première moitié du XVIII siècle à en juger par la facture des pilastres encadrant leurs portes d'accès ? Elle est en tout cas un fait acquis dans la seconde moitié du siècle, époque à laquelle il est d'usage d'appeler "passage " la galerie 0. (63).

Pour vraisemblables qu'elles soient, ces datations n'en restent pas moins hypothétiques : le dépouillement du registre des délibérations du Chapitre, qui est complet pour les XVII ${ }^{\mathrm{e}}$-XVIII ${ }^{\mathrm{e}}$ siècles, ne nous a fourni aucune indication de l'ouverture d'un chantier d'envergure dans le cloitre, et ce fait ne laisse pas d'inquiéter, quand on sait la minutie avec laquelle les chanoines traitaient leurs affaires.

(59) Archives des B.-d.-R.. liasse $2 G 490, f^{\circ} 252 r^{\circ}$. II reste sans doute de ce dispositif de clóture les rainures pratiquées sur les bases des colonnes géminées du cloitre pour permettre l'encastrement d'un grillage dont les gravures du ${ }_{\mathrm{VI}} \mathrm{X}^{\mathrm{e}}$ siècle et les photographies plus récentes ont conservé le souvenir.

(60) Par exemple dans la délibération du Chapitre du 13 mars 1768, ibid. 2G 496, ${ }^{\circ} 496$. $\mathrm{r}^{\circ}$ : "le passage (scil. des chapiteaux) sera carrelé avec de gros carreaux de carosse ". Il s'agit peut-être. on le notera. d'une réfection du carrelage de briques en épi dont on a retrouvé trace au pied du mur en grand appareil rebouchant la niche ou l'enfeu du mur de la galerie E.. à l'angle S.-E. du baptistère (fig. 22).

(61) J. Guyon. loc. cit., p. 204-205.

(62) J. Guyon. ibid., avec reproduction du fac-simile de l'inscription par le graveur de Fauris de Saint-Vincens, fig. 2, p. 201.

(63) Cr. supra, n. 60. 


\section{LES DERNIÈRES MODIFICATIONS}

Négligeant les réfections mineures, au demeurant indatables, on présentera seulement les transformations les plus notables, limitées aux galeries $\mathrm{E}$. et $\mathrm{N}$.

Une importante campagne de travaux a touché la grande salle voûté à l'E. du cloître qu'on a transformée en local à deux niveaux en créant à plus de $1 \mathrm{~m}$ au-dessus du sol primitif un plancher qui a condamné non seulement la petite porte médiévale du N. (supra, p. 134) mais aussi la porte monumentale du S. (supra, p. 140).

Il a fallu ouvrir une large fenêtre cintrée donnant du jour aux deux niveaux d'utilisation (fig. 16) et peut-être aussi étayer les fondations du mur E. de la galerie dont la solidité était compromise par l'approfondissement du local primitif : ainsi s'expliquerait la création d'un puissant contrefort entre la porte $\mathrm{N}$. et la nouvelle fenêtre, qui est collé contre le mur I qu'il masque très largement (mais il est vrai que les fondations peuvent avoir èté renforcées à tout moment de l'histoire complexe de la salle à l'E. du cloître). En tout cas, les assises de gros moellons qui constituent le contrefort s'élargissent à mesure que l'on s'abaisse, saillant à la base (à la cote $203,13 \mathrm{~m}$ ) de près de $0,80 \mathrm{~m}$; leur direction générale est oblique par rapport au mur dont elles se rapprochent progressivement à mesure qu'on s'éloigne vers le S. Pour construire cet ouvrage, on a ouvert une tranchée large de $0,40 \mathrm{~m}$, ultérieurement remblayée par des débris de pierre de taille et de mortier jaunâtre, sans autre matériel datable. Au N., la tranchée fut creusée directement dans le remblai antique et médiéval : plus au S. sa paroi 0 . a été renforcée par un mur, le mur VIII, qui est à l'évidence une construction provisoire, large de $0,20 \mathrm{~m}$ à $0,40 \mathrm{~m}$. constituée d'un parement de moellons adossé au remblai qu'elle étaie.

Pour dater ces travaux les vues du cloître au XIX ${ }^{e}$ siècle (tableau de Granet, gravures, lithographies) fournissent un terminus post quem non en montrant que la fenêtre illuminant la salle supérieure est déjà en fonction (celle de la salle inférieure peut n'avoir été ouverte qu'après coup, ou au contraire avoir été un moment rebouchée), et l'on peut donc placer au plus tard à la fin du XVIII siècle la transformation de la salle voûtée.

Dans la galerie N. l'interprétation et la datation des vestiges mis au jour sont plus conjecturales.

L'unique sondage qu'il a été possible d'ouvrir dans cette zone est en effet occupé pour l'essentiel par une tranchée très récente qui a détruit toute trace d'occupation jusqu'au niveau de la Basse-Antiquité. Aussi le contexte manque-t-il pour interpréter les vestiges retrouvés à l'E. de la tranchée, une installation de facture médiocre constituée de murets en moellons à la base, en briques au sommet qui délimitent une fosse large de $0,60 \mathrm{~m}$, longue d'au moins $1,30 \mathrm{~m}$ (l'extrémité $\mathrm{S}$. a été détruite par une coulée récente de béton) et profonde d'l $\mathrm{m}$. Une pierre - qui pouvait servir d'appui à une couverture en bois - barre transversalement la fosse à $0,50 \mathrm{~m}$ au $\mathrm{S}$ du mur $\mathrm{N}$., $0,80 \mathrm{~m}$ au-dessus du fond en terre.

Cette construction a été soigneusement arasée pour laisser place à un sol (à la cote $204,92 \mathrm{~m}$ ) pavé d'une calade en galets de rivière, très résistante au N., plus légère au S., elle-même recouverte par le pavement actuel constitué de briques posées de chant en épi. Aussi n'est-il pas étonnant qu'on ait retrouvé la fosse emplie d'un remblai; à la base de la stratigraphie figurait pourtant une couche cendreuse qui date sans doute de la période d'utilisation d'une construction dont la destination n'est pas claire : fosse à détritus? ou même lieu d'aisance?

La datation est également floue, la céramique vernissée moderne ou contemporaine recueillie dans la fouille montrant seulement qu'on doit songer à une époque récente.

Pour plus de précision, on pourrait penser à examiner à nouveau l'iconographie du cloitre, mais les indications qu'elle fournit sont contradictoires. Le tableau d'Auguste de Forbin (1829) ne présente aucune construction dans cette zone et une gravure de 1835, prise au N.-E., atteste que le sol au N. de la colonnade N. était alors déjà pavé de briques; une lithographie de 1843 montre en revanche l'existence d'un édicule sur l'emplacement approximatif du sondage 9 (64). Faut-il y voir l'élévation des vestiges mis au jour? et doit- on songer alors à une creation tardive, démolie plus tardivement encore ? ou bien les vues antérieures du cloître ont-elles volontairement simplifié la présentation du monument en supprimant l'édicule déjà existant ? On ne sait.

Il est sûr en tout cas qu'on atteint avec la disparition de cette dernière construction l'époque à laquelle le cloitre, devenu Monument historique, ne reçoit plus de transformations organiques, mais subit des restaurations plus ou moins importantes, qui ont consisté surtout à démolir les maisons installées au-dessus

(64) Le tableau d'A. de Forbin est au Musée du Louvre (réserves), les gravures de 1835 et 1843 sont consultables notamment à la B. N., Estampes, Va 13, t. 2. 
des galeries (65), suivant en cela un exemple déjà ancien, puisque les vues du XIX $X^{e}$ siècle montrent qu'à cette date, la galerie N., débarrassée de ses constructions parasites, n'est plus couverte. L'histoire précise de ces restaurations serait d'ailleurs intéressante à faire; mais ce serait, comme on dit, " une autre histoire ".

\section{Rollins GUILD, Jean GUYON, Lucien RIVET}

[Cette étude déborde assez largement vers le bas. du point de vue chronologique, le domaine réservé à la Revue Archéologique de Narbonnaise. Il a paru opportun de faire cette exception, pour èviter de scinder en plusieurs morceaux les résultats d'une fouille unique, qui rèvele la continuité de l'occupation humaine, de l'antiquité aux temps modernes, dans une zone d'intérêt capital pour l'histoire d'Aix-en-Provence. La Réd.].

(65) Commencée en 1915 par la démolition des constructions au-dessus de la galerie S., la restauration s'est poursuivie en 1958 par la suppression des bảtiments surmontant la galerie $\mathrm{O}$. 